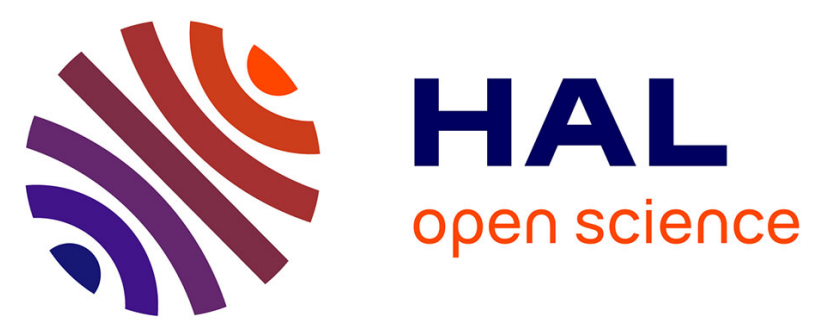

\title{
trans-Cinnamic acid, but not p-coumaric acid or methyl cinnamate, induces fibroblast migration through PKA- and p38-MAPK signalling pathways
}

Fernanda Lima Torres De Aquino, Juliane Pereira Da Silva, Jamylle Nunes de Souza Ferro, Vincent Lagente, Emiliano Barreto

\section{To cite this version:}

Fernanda Lima Torres De Aquino, Juliane Pereira Da Silva, Jamylle Nunes de Souza Ferro, Vincent Lagente, Emiliano Barreto. trans-Cinnamic acid, but not p-coumaric acid or methyl cinnamate, induces fibroblast migration through PKA- and p38-MAPK signalling pathways. Journal of Tissue Viability, 2021, 30 (3), pp.363-371. 10.1016/j.jtv.2021.05.003 . hal-03247621

\section{HAL Id: hal-03247621 \\ https://hal.science/hal-03247621}

Submitted on 15 Jun 2021

HAL is a multi-disciplinary open access archive for the deposit and dissemination of scientific research documents, whether they are published or not. The documents may come from teaching and research institutions in France or abroad, or from public or private research centers.
L'archive ouverte pluridisciplinaire HAL, est destinée au dépôt et à la diffusion de documents scientifiques de niveau recherche, publiés ou non, émanant des établissements d'enseignement et de recherche français ou étrangers, des laboratoires publics ou privés. 
trans-Cinnamic acid, but not $p$-coumaric acid or methyl cinnamate, induces fibroblast migration through PKA- and p38-MAPK signalling pathways

Fernanda Lima Torres de Aquino ${ }^{a}$, Juliane Pereira da Silva ${ }^{a}$, Jamylle Nunes de Souza Ferro $^{\mathrm{a}}$, Vincent Lagente ${ }^{\mathrm{b}}$, Emiliano Barreto $^{\mathrm{a} *}$

Affiliations:

${ }^{a}$ Laboratory of Cell Biology, Federal University of Alagoas, 57072-900, Maceió-Brazil.

b NuMeCan Institute (Nutrition, Metabolism and Cancer), Université de Rennes, INSERM, INRA, F-35000 Rennes, France.

* Corresponding author at: Laboratory of Cell Biology. Campus A.C. Simões, s/n. Tabuleiro dos Martins. CEP 57072-970. Maceió, Alagoas, Brazil. Tel.: +55 8232141704

E-mail address: emilianobarreto@icbs.ufal.br (E. Barreto).

\section{Acknowledgments}

This study was supported by the Conselho Nacional de Desenvolvimento Científico e Tecnológico (CNPq, 308898/2018-4). This work was conducted during a scholarship supported by the International Cooperation Program CAPES/COFECUB Foundation at the University of Rennes-FR. Financed by CAPES - Brazilian Federal Agency for Support and Evaluation of Graduate Education within the Ministry of Education of Brazil.

Declarations of interest: none 
trans-Cinnamic acid, but not $p$-coumaric acid or methyl cinnamate, induces fibroblast migration through PKA- and p38-MAPK signalling pathways

\begin{abstract}
Aim: Hydroxycinnamic acids their derivatives have various pharmacological properties. The hydroxycinnamic acid derivatives, methyl cinnamate, trans-cinnamic, and $p$ coumaric acids have been the object of study in the treatment of skin wounds. However, it is unclear whether these derivatives exert a direct beneficial effect on fibroblast function. In this study, we evaluated the effects of methyl cinnamate, trans-cinnamic, and $p$-coumaric acids on fibroblast migration in vitro.

Materials and methods: NIH 3T3 and L929 fibroblast cell lines were exposed to each drug at several concentrations and the effect on cell viability, cell cycle, and extracellular matrix production were assessed by MTT assay, flow cytometry, and immunofluorescence staining, respectively. The effect on cell migration was examined using scratch assay.
\end{abstract}

Results: The results showed that hydroxycinnamic acid derivatives not affect cell viability, but increase fibroblast migration in the in vitro scratch-wound healing assay. They also induced an increase in S and G2/M phases accompanied by a decrease in the G0/G1 phase of the cell cycle. The cell proliferation inhibitor mitomycin C abolished the effect induced by $p$-coumaric acid and methyl cinnamate, indicating that only the trans-cinnamic acid stimulated migration. A transwell migration assay confirmed that trans-cinnamic acid-treated fibroblasts exhibited increased migration compared with untreated cells. trans-Cinnamic acid-induced fibroblast migration was decreased by PKA inhibitor and p38-MAPK inhibitor but not by JNK inhibitor. Additionally, trans- 
cinnamic acid-treated fibroblasts showed an increase in the production of laminin and collagen type I.

Conclusion: Our study showed that trans-cinnamic acid improves fibroblast migration and modulates extracellular matrix synthesis, indicating its potential for accelerating the healing process.

Keywords: fibroblast; trans-cinnamic acid; methyl cinnamate; $p$-coumaric acid; wound healing 


\section{Introduction}

Wound healing is a dynamic process involving complex biological and molecular events, which requires the participation of many types of cells, including macrophages, keratinocytes, endothelial cells, and fibroblasts [1]. During this process, fibroblasts play an important role by depositing extracellular matrix (ECM) [2]. which guides angiogenesis [3] and supports the migration and proliferation of other cells that eventually form the scar [4]. Thus, drugs targeting fibroblast function may contribute to skin wound healing.

The increasing popularity of natural therapies has stimulated research into the use of plant-derived compounds for wound management $[5,6]$. It is worth pointing out that medicinal plants containing phenolic compounds, such as the species Achyrocline alata, Strychnos pseudoquina, and Grammatophyllum speciosum have been used in traditional medicinal practices worldwide to treat skin wounds [7-9]. Indeed, phytochemicals have been used to treat wounds for years. In particular, hydroxycinnamic acid derivatives are an important group of compounds present in fruits and foods, including apples, pears, peas, beans, and tomatoes, that exhibit a wide spectrum of biological activities [10]. Recent studies have reported that hydroxycinnamic acids exert health-promoting effects such as reduction of blood glucose levels [11] and possess anti-microbial, anti-tumour, anti-inflammatory, and wound healing properties $[12,13]$.

Hydroxycinnamic acids derivatives such as trans-cinnamic acid, p-coumaric acid, and methyl cinnamate have been reported to possess antioxidant effects, an important characteristic for wound healing [6]. Moreover, it has been reported that trans-cinnamic acid ameliorates the UVA-induced dermatotoxic effects on human dermal fibroblasts and mouse skin [14]. In addition, trans-cinnamic acid also increases 
the capability of phagocytic innate immune cells, a phenomenon important for the healing process [15]. Studies have also found that $p$-coumaric acid has free radical scavenging ability, anti-ulcer activity [16], and stimulates bone formation [17]. Previous studies have demonstrated the effect of methyl cinnamate on inducing nitric oxide, an important inducer of collagen deposition and stimulator of wound healing [18]. In addition, hydroxycinnamic acid derivatives also stimulates distinct intracellular signaling pathways such as protein kinase A (PKA), c-Jun N-terminal kinase (JNK) and mitogen-activated protein kinases (MAPK) [19], which are associated with multiple biological functions, including changes in the actin cytoskeleton, migration and extracellular matrix (ECM) production [20]. All properties listed above indicate the potential of hydroxycinnamic acid derivatives in promoting wound healing. However, the effects of trans-cinnamic acid, methyl cinnamate, and $p$-coumaric acid on fibroblast functions related to healing, such as migration, have not been demonstrated previously.

Thus, the aim of this study was to evaluate the effect of the three hydroxycinnamic acid derivatives, trans-cinnamic acid, methyl cinnamate, and $p$ coumaric acid, on fibroblast migration and suggest the underlying mechanism. Moreover, their effect on the synthesis of ECM and the cell cycle was also investigated.

\section{Methods}

\subsection{Chemical and reagents}

The following reagents were purchased from Sigma Chemical Co. (St. Louis, MO, USA): trans-cinnamic acid (PubChem CID: 444539, Figure 1A), p-coumaric acid (PubChem CID: 637542, Figure 1B), methyl cinnamate (PubChem CID: 637520, Figure 
1C), Tween-20, dimethyl sulfoxide (DMSO), phosphate-buffered saline (PBS), Dulbecco's modified Eagle medium (DMEM), mitomycin C, propidium iodide (PI), methylthiazolyldiphenyl-tetrazolium bromide (MTT), 4',6-diamidino-2'-phenylindole dihydrochloride (DAPI), SB203580 (p38-MAPK inhibitor), JNK-IN-8 (inhibitor of JNK1/2/3), and PKI-(6-22)-amide (inhibitor of cAMP-dependent protein kinase, CREB). Foetal bovine serum (FBS), trypsin, penicillin, streptomycin, and L-glutamine were purchased from Invitrogen (Carlsbad, CA, USA). Antibodies against laminin, fibronectin, and collagen type I were purchased from Novotec (St. Martin-LaGarenne, France), while anti-goat IgG-fluorescein isothiocyanate (FITC) was from Santa Cruz Biotechnology (CA, USA).
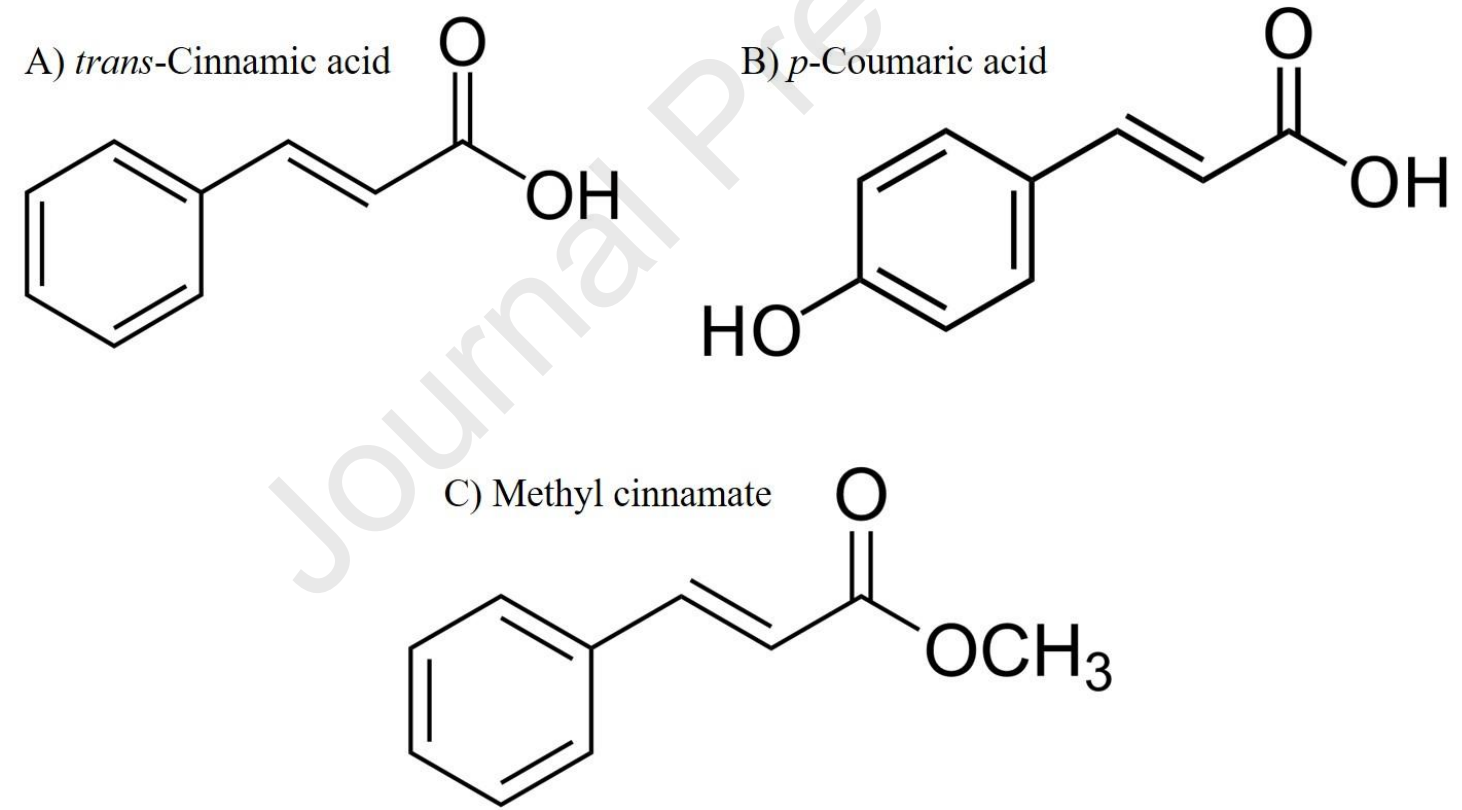

Figure 1. The chemical structure of the trans-cinnamic acid (A), p-coumaric acid (B), and methyl cinnamate $(\mathrm{C})$ used in the present study.

\subsection{Cell culture}

NIH 3 T3 mouse embryonic fibroblasts or L929 fibroblast cell line were cultured in DMEM, supplemented with $10 \%$ FBS, $2 \mathrm{mM}$ L-glutamine, and $0.02 \%$ penicillin/streptomycin, at $37^{\circ} \mathrm{C}$ in a humidified atmosphere containing $5 \% \mathrm{CO}_{2}$. The 
assay was performed using cells between 3 and 5 passages. Hydroxycinnamic acid derivatives were dissolved in DMSO and then diluted with DMEM. The final concentration of DMSO during treatments did not exceed $0.1 \%(\mathrm{v} / \mathrm{v})$ in cell cultures. DMEM containing of dimethyl sulfoxide (0.1\% DMSO) was used as the vehicle.

\subsection{Cell viability assay}

The effect of trans-cinnamic acid, p-coumaric acid, and methyl cinnamate on cell viability was evaluated by the MTT assay [21]. NIH 3T3 fibroblasts were plated in 96-well plates $\left(7 \times 10^{3} /\right.$ well) and treated with vehicle (negative control) or hydroxycinnamic acid derivatives at concentrations of 3,30 , and $300 \mu \mathrm{M}$ for $24 \mathrm{~h}$. Cells lysed by $1 \%$ Triton-X-100 were used as the positive control. Next, the medium was replaced with fresh DMEM containing $5 \mathrm{mg} / \mathrm{mL}$ MTT and the plates were incubated for

a further for $4 \mathrm{~h}$ in a humidified $\mathrm{CO}_{2}$ incubator at $37{ }^{\circ} \mathrm{C}$ and $5 \% \mathrm{CO}_{2}$. The resulting culture supernatant was removed and DMSO (150 $\mu \mathrm{L} /$ well) was added to each culture plate. After incubation at room temperature for $15 \mathrm{~min}$, the absorbance of the solubilized MTT formazan product was spectrophotometrically measured at $540 \mathrm{~nm}$. Three individual wells were assayed for each treatment, and the percentage viability relative to the control sample was determined as (absorbance of treated cells/absorbance of untreated cells $) \times 100 \%$.

\subsection{Scratch wound healing assay}

The scratch wound-healing assay was applied as previously described [22]. NIH 3 T3 fibroblast cells $\left(2 \times 10^{5}\right)$ were seeded into each well of a 24 -well plate and maintained for $24 \mathrm{~h}$ until they reached $90 \%$ confluency. Next, a $200 \mu \mathrm{l}$ sterile pipette tip was used to create a straight cell-free scratch. The wells were washed with PBS to 
remove dead cells and debris, and then subjected to treatment with $30 \mu \mathrm{M}$ of transcinnamic acid, $p$-coumaric acid, or methyl cinnamate in serum-free medium. As a control, the cells were treated with vehicle. After 8,12 or $24 \mathrm{~h}$ of treatment with hydroxycinnamic acid derivatives, the cells that migrated onto the scratched region were photographed using an inverted microscope with a digital camera (Nikon Eclipse TS100, Nikon Corporation, Tokyo, Japan). In another set of experiments, the scratched monolayer was treated with $10 \mu \mathrm{M}$ SB203580, $10 \mu \mathrm{M}$ JNK-IN-8, or $10 \mu \mathrm{M}$ PKI-(6-22)amide, followed by the addition of $30 \mu \mathrm{M}$ trans-cinnamic acid for $24 \mathrm{~h}$.

The same procedure described above was used to evaluate the effect of transcinnamic acid, p-coumaric acid, or methyl cinnamate on L929 dermal fibroblast cell migration. After reaching confluence, the monolayer of L929 fibroblasts was scratched. Cells were then treated with $30 \mu \mathrm{M}$ of trans-cinnamic acid, $p$-coumaric acid, or methyl cinnamate. As a control, the cells were treated with vehicle (DMSO 0.1\% in DMEM). After $24 \mathrm{~h}$ of treatment, cells were photographed using an inverted microscope with a digital camera to measure wound closure. To prevent cell proliferation, mitomycin $\mathrm{C}$ (4 $\mu \mathrm{g} / \mathrm{ml}$ ) was added to each well, including vehicle and hydroxycinnamic acid derivatives-treated cells; this ensured that only migration contributed to wound closure. Cell migration was analysed using ImageJ software, and was expressed as the percentage of closure of the initial wound (scratch width at time zero) using the control group (vehicle) as $100 \%$ and the experimental group compared with the control group to ascertain the difference between the groups. Hydroxycinnamic acid derivatives-exposed and vehicle control cultures were compared. All the experiments were done in triplicate and repeated 3 times.

\subsection{Transwell migration assay}


Migration assays were performed using a method described by Suvarna et al. (2018) [22] using 24-well culture chambers and transwell inserts with polycarbonate membranes (diameter, $10 \mathrm{~mm}$; pore size, $8.0 \mu \mathrm{m}$; Corning Costar, Cambridge, USA). NIH 3 T3 fibroblasts $\left(5 \times 10^{4}\right)$ were seeded into the upper chamber in $200 \mu \mathrm{L}$ DMEM medium devoid of serum and containing $30 \mu \mathrm{M}$ trans-cinnamic acid. As a control, the cells were treated with vehicle (DMSO 0.1\% in DMEM). Cells were allowed to migrate for 8 hours at $37^{\circ} \mathrm{C}$ in a $5 \% \mathrm{CO}_{2}$ incubator. At the end of the incubation period, the membrane was fixed with $3.7 \%$ formaldehyde, and stained with $1 \%$ crystal violet and subjected to inverted microscope image under $10 \times$ objective. Cells that penetrated the filter were counted in three predetermined fields. Three independent experiments were performed, each performed in triplicate, and a representative image is shown.

\subsection{Cell-cycle analysis}

The cell cycle analysis using flow cytometry was carried out as described previously by Pozarowski and Darzynkiewicz (2004) [23]. In brief, cells were seeded on 24-well plates $\left(6 \times 10^{4}\right.$ cells/well), and $24 \mathrm{~h}$ later, these cells were treated with vehicle (DMSO $0.1 \%$ in DMEM) or hydroxycinnamic acid derivatives $(30 \mu \mathrm{M})$. Subsequently, cells were trypsinized, washed with PBS, and then fixed in $70 \%$ ice-cold ethanol for 1 h. Later, the ethanol was removed by centrifugation $(460 \times \mathrm{g}$ for $10 \mathrm{~min})$, and the cell pellets were resuspended in $500 \mu \mathrm{L}$ of DNA-staining buffer containing $5 \mu \mathrm{g} / \mathrm{mL}$ PI, $1 \%$ Triton X-100, and $0.05 \mathrm{mg} / \mathrm{mL}$ RNase. After $30 \mathrm{~min}$ of incubation at room temperature in the dark, cells were examined using the FACSCanto II flow cytometer system (BD Biosciences, San Jose, CA, USA).

\subsection{Immunofluorescence staining}


Fibroblasts $\left(6 \times 10^{4}\right)$ were cultured in 8-well Lab-tek chamber glass slides (Nunc, NY, USA) with complete medium (DMEM) for $24 \mathrm{~h}$. The medium was then replaced and the cells were treated with $30 \mu \mathrm{M}$ of trans-cinnamic acid for $24 \mathrm{~h}$. Cells maintained in vehicle (DMSO 0.1\% in DMEM) under the same conditions were used as controls. After treatment, the cultures were washed with PBS, fixed with $100 \%$ methanol for 10 min, and subjected to an indirect immunofluorescence assay, as previously described Smaniotto et al. (2005) [24]. Briefly, cells were rehydrated in PBS and incubated for $1 \mathrm{~h}$ with PBS containing $1 \%$ BSA to block non-specific binding. Next, samples were incubated with primary specific anti-laminin, anti-fibronectin, or anti-collagen type I antibodies (1:50) for $1 \mathrm{~h}$ in a humidified chamber, washed with PBS, and incubated with appropriate FITC-conjugated secondary antibody (1:200) for $45 \mathrm{~min}$ at room temperature. DAPI staining was used to visualize the nuclei. Immunostained samples were analysed by fluorescence microscopy. Controls comprised specimens in which primary antibodies were replaced by unrelated Igs and generated no significant labelling. The staining of each section was analysed to obtain a mean optical density value (MOD), which represented the strength of the staining signal per positive $\operatorname{pixel} / \mu \mathrm{m}^{2}[25]$.

\subsection{Statistical analysis}

Data are reported as mean \pm standard deviation $(\mathrm{SD})$ and were analysed using GraphPad Prism software, version 5.0 (San Diego, CA, USA). Comparisons between the experimental groups were performed either by one-way ANOVA followed by Tukey's test, or by two-way ANOVA followed by the Bonferroni post hoc test. P values less than 0.05 were considered statistically significant. 


\section{RESULTS}

\subsection{Effect of trans-cinnamic acid, p-coumaric acid, or methyl cinnamate on cell} viability

The MTT assay was used to test the potential cytotoxic effect of the hydroxycinnamic acid derivatives on fibroblasts. As presented in Figure 2, we identified that the fibroblast viability was not significantly affected by treatment for $24 \mathrm{~h}$ with trans-cinnamic acid, $p$-coumaric acid, or methyl cinnamate at doses 3, 30, or $300 \mu \mathrm{M}$.

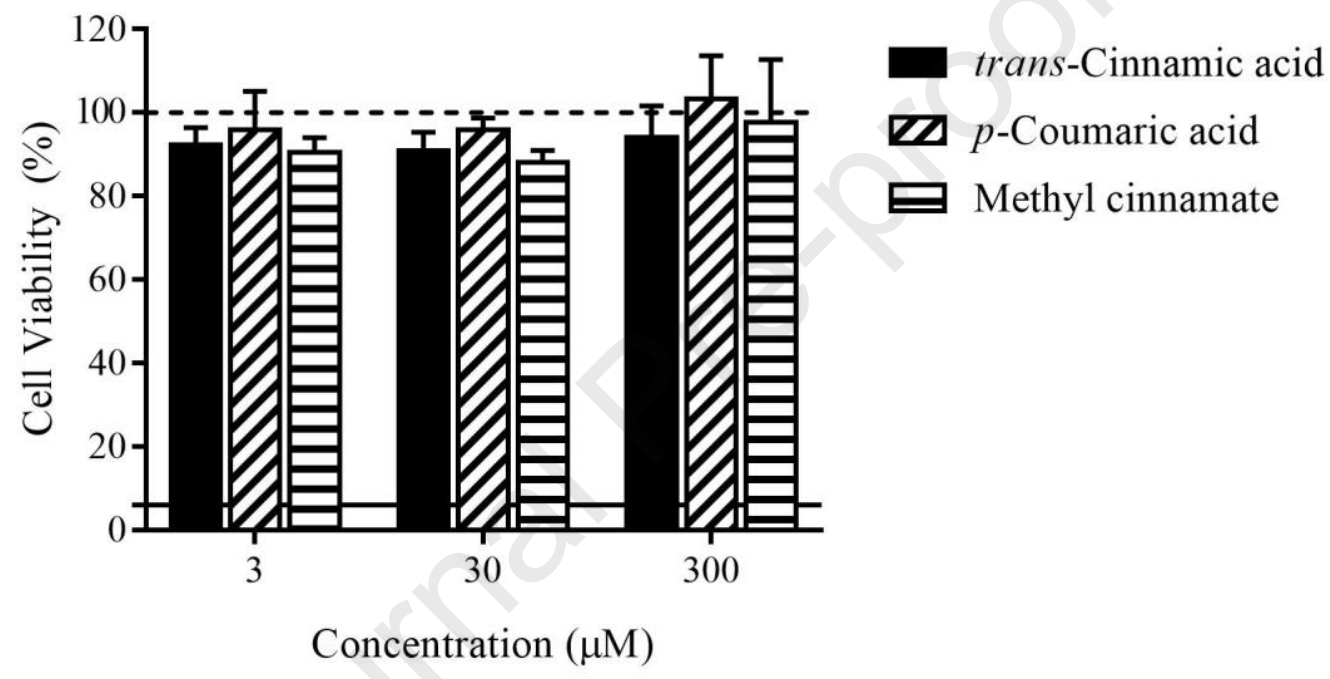

Figure 2. Effect of trans-cinnamic acid, p-coumaric acid, or methyl cinnamate on the viability of NIH 3 T3 fibroblasts. Cells were plated at $7 \times 10^{3}$ cells/well and treated with hydroxycinnamic acid derivatives $(3-300 \mu \mathrm{M})$ for $24 \mathrm{~h}$. Cell viability was measured by MTT assay. The dashed line represents cells maintained only with vehicle (DMSO $0.1 \%$ in DMEM), while the solid line represents the cells lysed by $1 \%$ Triton-X-100 (positive control). The bars represent mean \pm SD of three independent experiments, each performed in triplicate.

\subsection{Effects of hydroxycinnamic acid derivatives treatment on fibroblast motility}

The effect of trans-cinnamic acid, $p$-coumaric acid, or methyl cinnamate on fibroblast migratory activity was examined using a scratch assay. Scratches were made on the monolayer of confluent cells and then treated with vehicle or hydroxycinnamic 
acid derivatives at concentration of $30 \mu \mathrm{M}$. Cell migration into the scratch area was evaluated at 8, 12 and $24 \mathrm{~h}$. As shown in Figure 3A, fibroblasts treated with transcinnamic acid, $p$-coumaric acid, or methyl cinnamate exhibited a faster scratch closure rate compared to vehicle (control). In Figure 3B, after 8, 12, and $24 \mathrm{~h}$ of culture, basal levels of scratch closure in vehicle-treated cells were $10 \%, 16 \%$ and $29 \%$ respectively, while fibroblasts cultured in the presence of $30 \mu \mathrm{M}$ of trans-cinnamic acid exhibited respectively, an increase in migration to $19 \%$ at 8 hours, $26 \%$ at 12 hours and $52 \%$ at 24 hours. A similar profile of migration occurred in cells cultured with $30 \mu \mathrm{M} p$-coumaric acid (Figure 3B), where cells had their migratory capacity increased to $15 \%$ at 8 hours, $20 \%$ at 12 hours and $40 \%$ at 24 hours (Figure 3B). As observed in the two preceding treatments, exposure of the cells to $30 \mu \mathrm{M}$ of methyl cinnamate increased the migration rate to $13 \%$ at 8 hours, $23 \%$ at 12 hours and $37 \%$ at 24 hours (Figure $3 \mathrm{~B}$ ). 

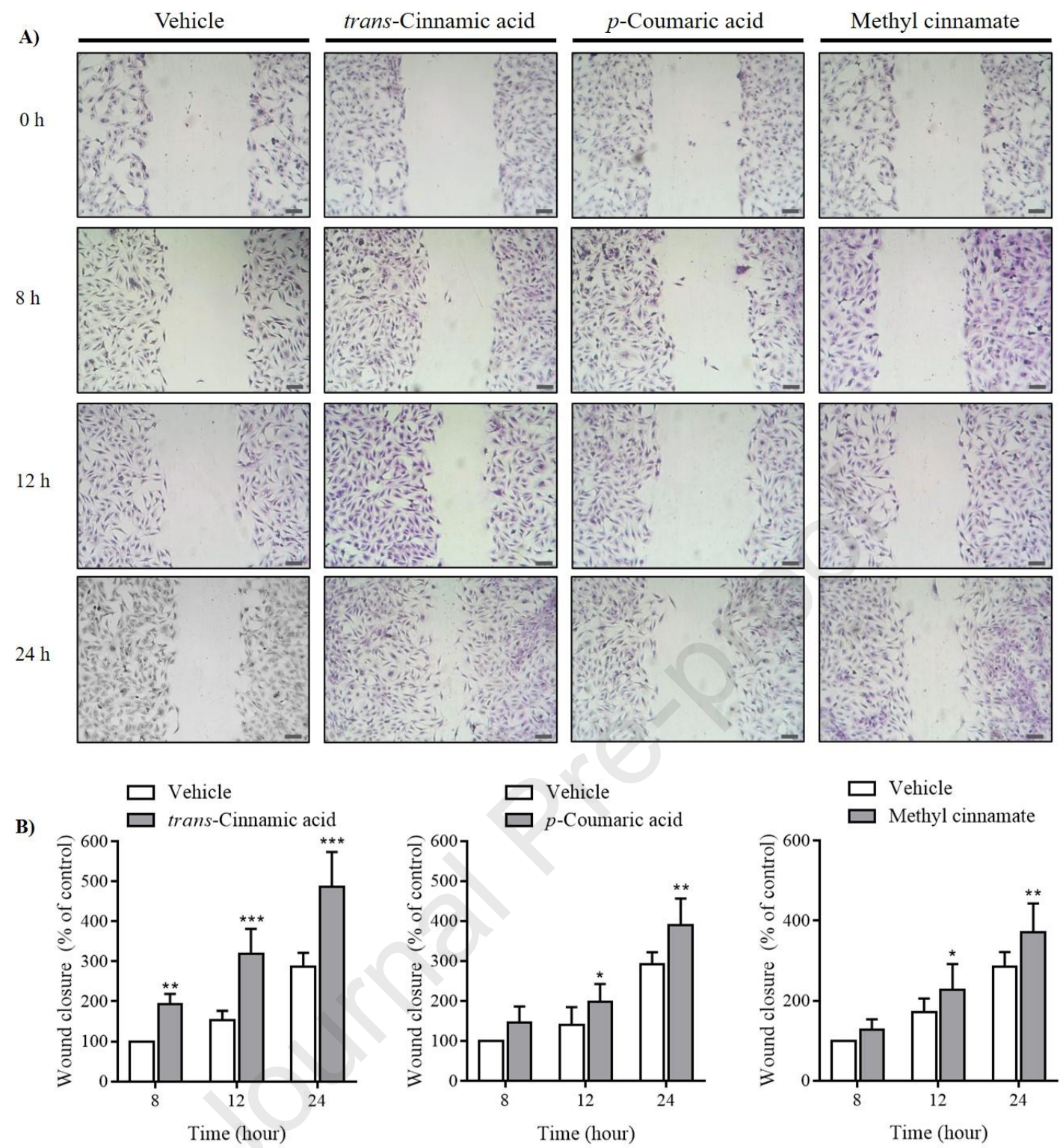

Figure 3. The effect of trans-cinnamic acid, $p$-coumaric acid, and methyl cinnamate on the cell migration of NHI $3 \mathrm{~T} 3$ fibroblasts assayed by the scratch assay. Fibroblasts were treated with $30 \mu \mathrm{M}$ of each hydroxycinnamic acid derivative, and images were captured to calculate the scratch closure. A) Representative photomicrography images showing the scratch area of cells treated with vehicle (DMSO 0.1\% in DMEM), trans-cinnamic acid, $p$-coumaric acid, or methyl cinnamate and the cell migration towards the cell-free area after 8,12 and $24 \mathrm{~h}$. Scale bars, $50 \mu \mathrm{m}$. B) The percentage of scratch covered was measured by quantifying the total distance the cells moved from the edge of the scratch towards the center of the scratch, using ImageJ software, followed by conversion to a percentage of the wound covered. The bars represent mean $\pm \mathrm{SD}$ of three independent experiments, each performed in triplicate. $\left({ }^{*}\right) \mathrm{P}<0.05,(* *) \mathrm{P}<0.01$ and $(* * *) \mathrm{P}<$ 0.001 compared with vehicle-treated cells at the respective time points. 
We also used the established L929 fibroblast cell line in the scratch assay to assess the effects of hydroxycinnamic acid derivative on fibroblast migration. Figure 4A shows representative images captured under the inverted microscope of cells treated with vehicle (DMSO 0.1\% in DMEM), trans-cinnamic acid, $p$-coumaric acid, or methyl cinnamate. As indicated in Figure 4B, quantitative analysis of the migratory response of L929 fibroblasts treated with mitomycin $\mathrm{C}(4 \mu \mathrm{g} / \mathrm{ml})$ and exposed to trans-cinnamic acid $(30 \mu \mathrm{M})$ showed a significant increase in total migration at 24 hours post-scratch. However, the migratory response of L929 fibroblasts was only slightly increased by treatment with $p$-coumaric acid or methyl cinnamate, and these increases, compared with vehicle-treated cells, were not significant.
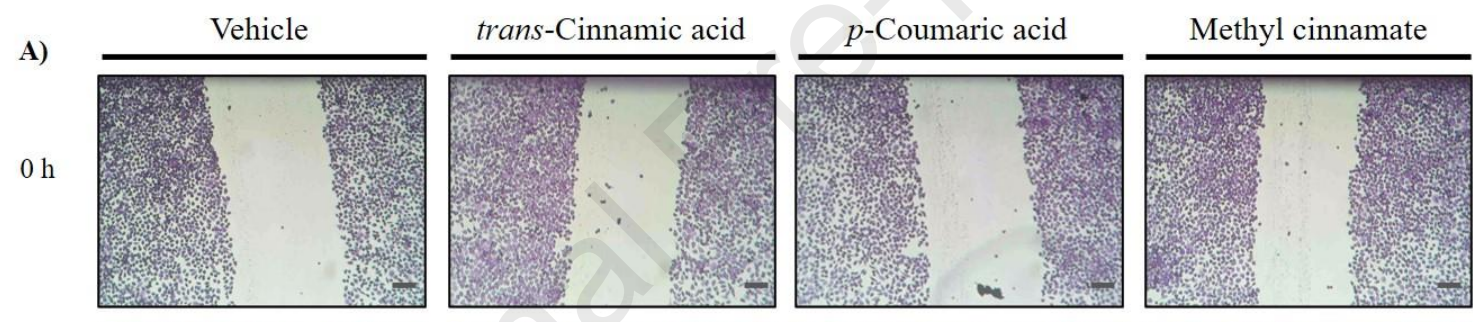

$18 \mathrm{~h}$
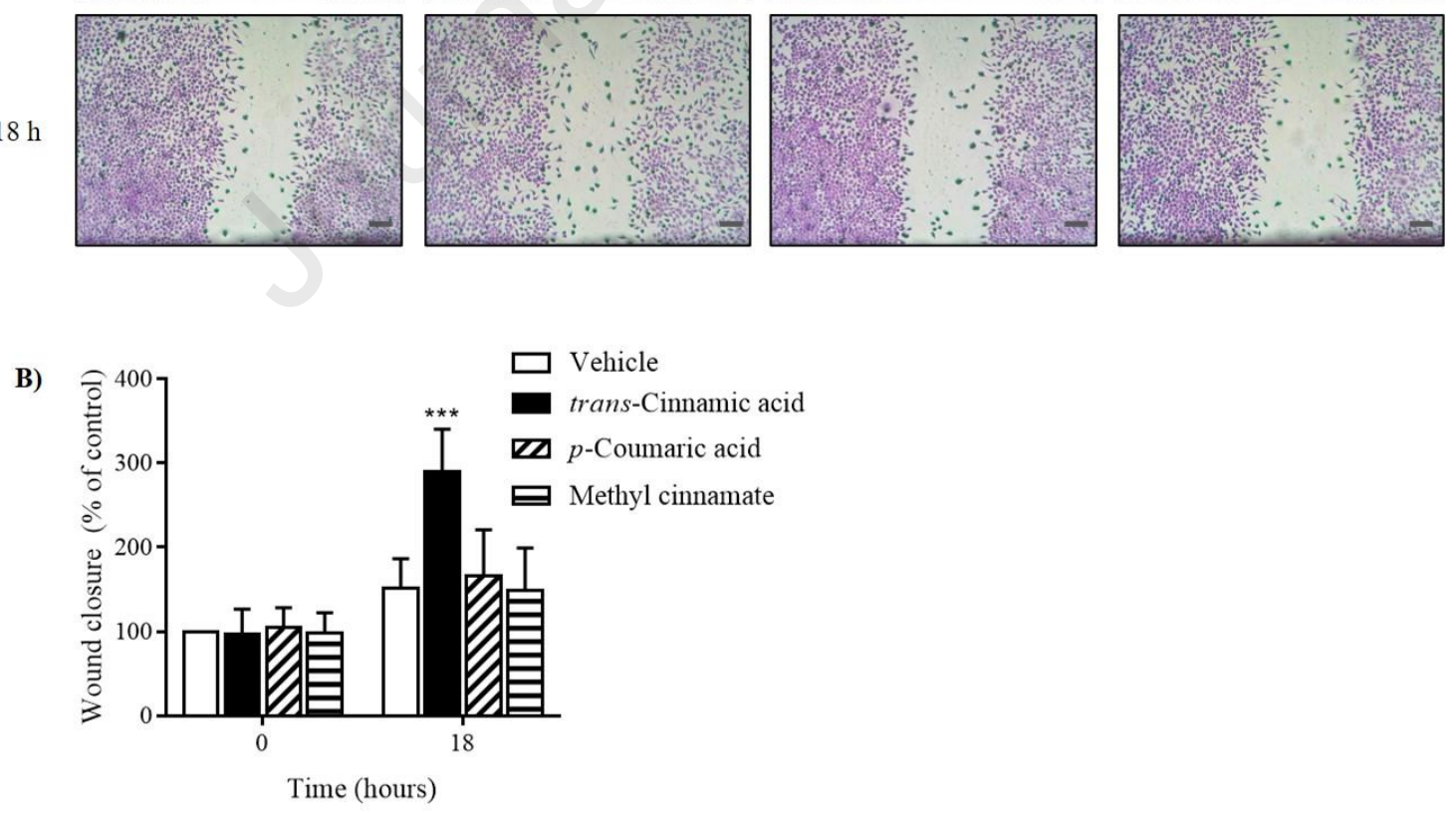

Figure 4. The effect of trans-cinnamic acid, p-coumaric acid, and methyl cinnamate on cell migration by L929 fibroblasts, assayed by the scratch assay. Fibroblasts were treated with $30 \mu \mathrm{M}$ of each hydroxycinnamic acid derivative or vehicle (DMSO $0.1 \%$ in DMEM), and photomicrographs were captured to calculate scratch closure. A) Representative photomicrographic images showing the scratch area of cells treated with 
vehicle, trans-cinnamic acid, $p$-coumaric acid, or methyl cinnamate, and cell migration into the cell-free area after 24 hours. Scale bars, $50 \mu \mathrm{m}$. B) The percentage of scratch covered was measured by quantifying the total distance the cells moved from the edges of each scratch towards the center, using ImageJ software, followed by conversion to a percentage of the wound covered. The bars represent mean \pm SD of three independent experiments, each performed in triplicate. $(* * *) \mathrm{P}<0.001$ compared with respective vehicle-treated groups at time 0 .

\subsection{The effect of hydroxycinnamic acid derivatives on cell cycle progression and migration}

To determine the effect of each hydroxycinnamic acid derivative on cell cycle progression, flow cytometry was performed. As shown in Figure 5, cells cultured in vehicle for $24 \mathrm{~h}$ (control group) exhibited a cell cycle distribution at G0/G1, S, and $\mathrm{G} 2 / \mathrm{M}$ phases of $77.4 \%, 5.9 \%$, and $16.7 \%$, respectively. Compared with the control group, the group treated with $30 \mu \mathrm{M}$ of trans-cinnamic acid showed a reduction in the G0/G1 phase population to $66.8 \%$ and a concomitant $16.7 \%$ increase in the S phase population without any change in the G2/M phase population (16.5\%) (Figure 5). Similarly, the treatment with $p$-coumaric acid or methyl cinnamate decreased, respectively, the cells in G0/G1 phase to $66.9 \%$ and $68 \%$ and, simultaneously, increased the cell population in S phase to $13.7 \%$ and $14.7 \%$, while maintaining the numbers of cells in G2/M phase at $19.4 \%$ and $17.3 \%$, respectively (Figure 5). These results indicate that a proliferative state of the fibroblasts was induced by treatment with the hydroxycinnamic acid derivatives. 


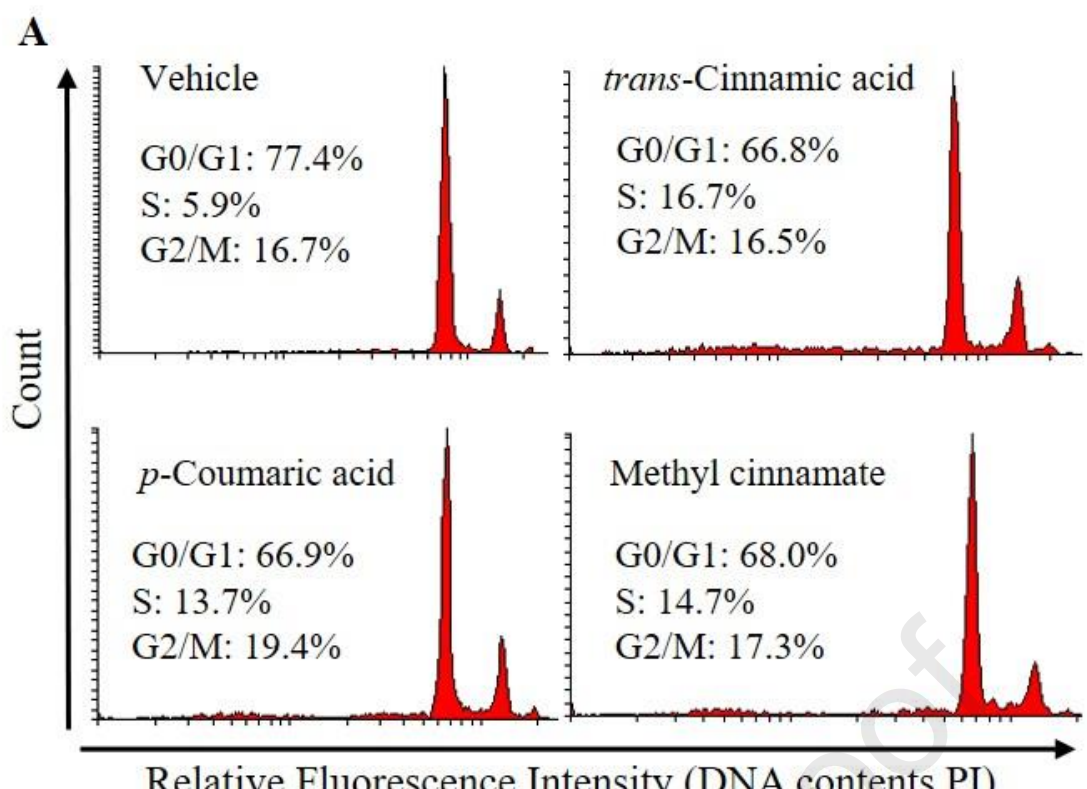

Relative Fluorescence Intensity (DNA contents PI)

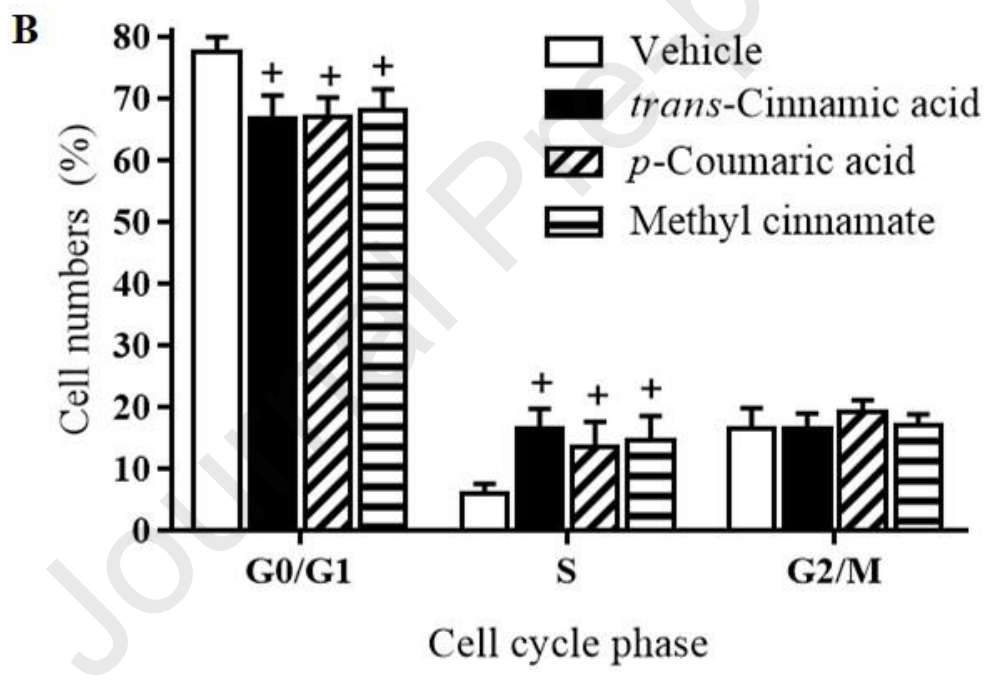

Figure 5. Effect of trans-cinnamic acid, $p$-coumaric acid, and methyl cinnamate on cell cycle progression in fibroblasts. Cells were exposed to the treatment for $24 \mathrm{~h}$. Cell cycle progression in fibroblasts was assessed by flow cytometry by analysing propidium iodide fluorescence in the slow acquisition and with doublet discrimination; 10,000 events were recorded. A) Histogram showing cell cycle of cells treated with $30 \mu \mathrm{M}$ hydroxycinnamic acid derivatives. B) Quantification of G0/G1-, S-, and G2/M-stage in fibroblasts. The bars represent mean \pm SD of three independent experiments, each performed in triplicate. Statistical significance between groups was determined by ANOVA followed by Bonferroni's test. $(+) \mathrm{P}<0.05$ compared with vehicle-treated cell in the respective phase. 
To eliminate the possibility that the scratch wound closure is dependent on proliferation, we treated the fibroblasts with mitomycin $\mathrm{C}$, a potent inhibitor of cell proliferation. As shown in Figure 6A, cells were pre-treated with $4 \mu \mathrm{g} / \mathrm{ml}$ of mitomycin $\mathrm{C}$ for $1 \mathrm{~h}$ and then exposed to $30 \mu \mathrm{M}$ hydroxycinnamic acid derivatives for $24 \mathrm{~h}$. It was observed that the cell proliferation was halted by mitomycin $\mathrm{C}$, while the migratory response was maintained at approximately $54 \%$ when compared to vehicle-treated cells (white bars). However, the migratory response of fibroblasts after treatment with $p$ coumaric acid or methyl cinnamate was reduced to the basal levels after exposure to mitomycin C (Figure 6A). This situation was different from that where fibroblasts were pre-treated with trans-cinnamic acid, wherein mitomycin $\mathrm{C}$ treatment did not cause a significant reduction in migratory response of fibroblasts (Figure 6A).

To confirm the effect of trans-cinnamic acid on migration, we performed transwell migration assays (Figure 6B). NIH 3T3 fibroblasts were seeded into the upper chamber with the filters, and were allowed to migrate for 8 hours. trans-Cinnamic acidtreatment resulted in a significant (close to 50\%) increase in fibroblast migration (Figure 6B), thereby reinforcing the suggestion that trans-cinnamic acid plays a direct role in fibroblast migration in vitro. 
A)

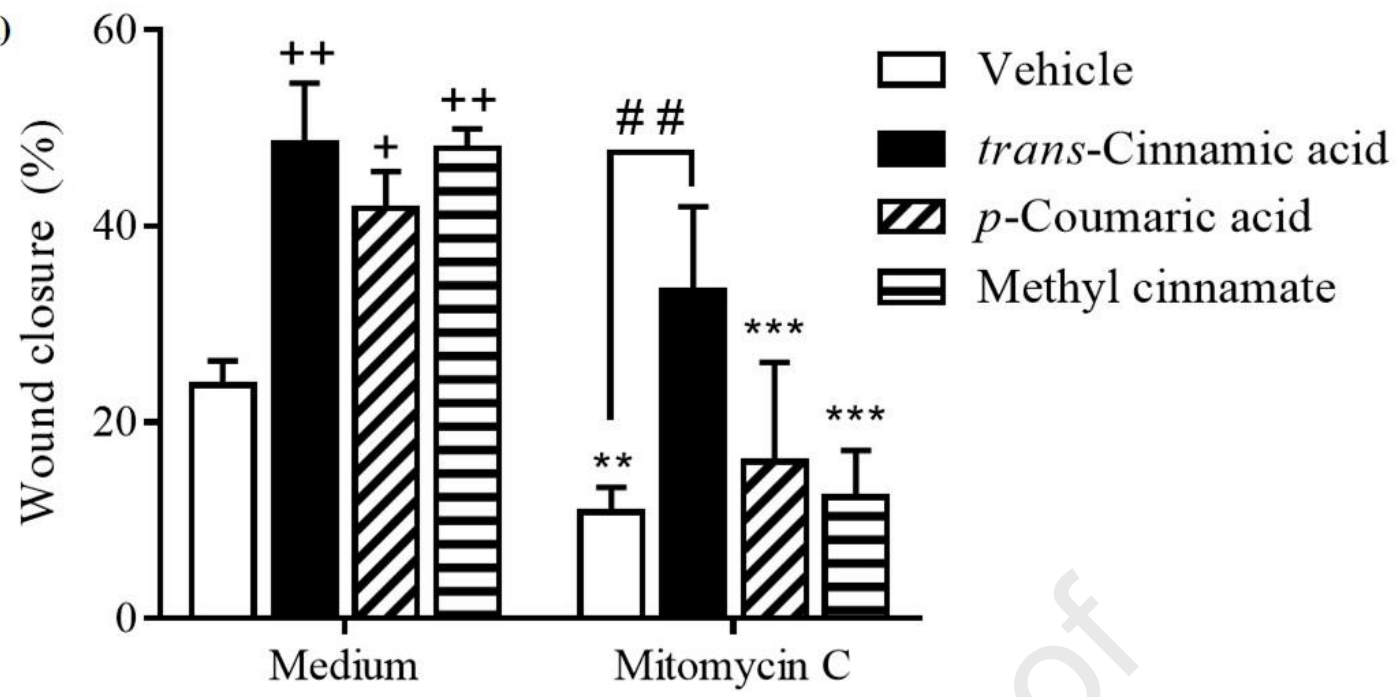

B)

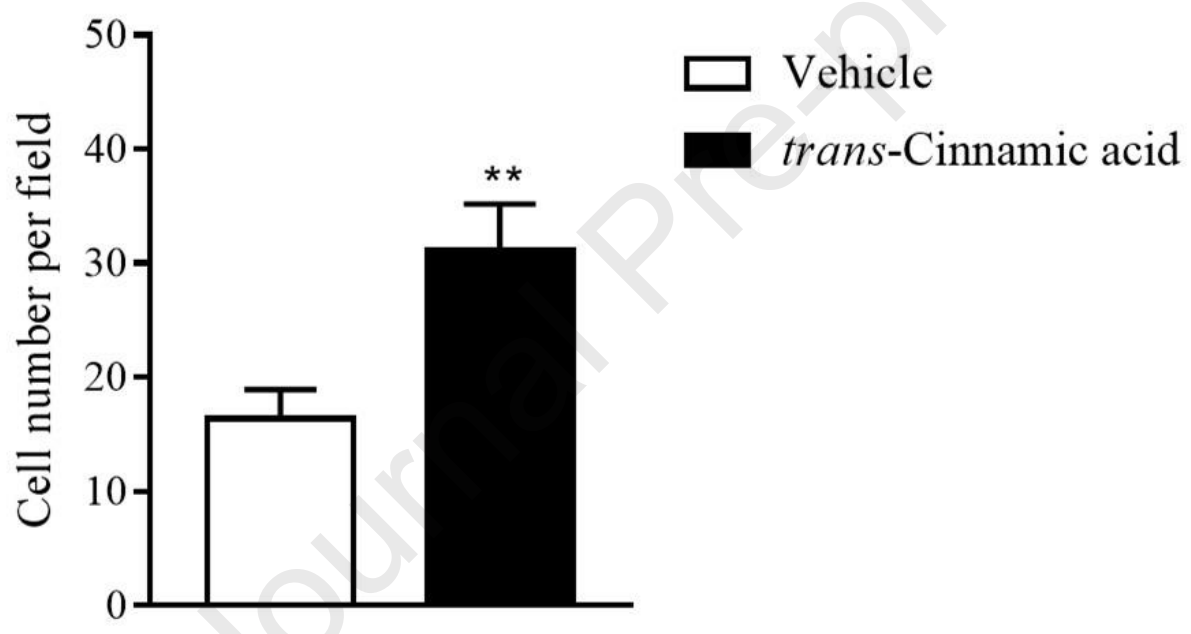

Figure 6. trans-Cinnamic acid promotes fibroblast migration. A) NIH 3 T3 fibroblasts were treated with mitomycin $\mathrm{C}$ before adding $30 \mu \mathrm{M}$ of each hydroxycinnamic acid derivative. Cell migration in the scratch assay was determined by photomicrography at 0 - and 24-hours post scratch with the aid of an inverted microscope. B) NIH 3T3 Fibroblast migration analyses via transwell cell migration assay. Cells were seeded into transwell chambers in serum-free medium containing $30 \mu \mathrm{M}$ trans-cinnamic acid or vehicle (DMSO $0.1 \%$ in DMEM), and allowed to migrate across the membranes for 8 hours. Membranes were stained with crystal violet, and images were captured with an inverted microscope. Bars represent mean \pm SD of three independent experiments, each performed in triplicate. Statistical significance between groups was determined by ANOVA followed by Bonferroni's test. $(+) \mathrm{P}<0.05$ and $(++) \mathrm{P}<0.01$ compared with medium-treated cells, $(* *) \mathrm{P}<0.01$ and $(* * *) \mathrm{P}<0.001$ compared with vehicle-treated cells. (\# \# P $<0.01$ ). 


\subsection{The role of the p38-MAPK, JNK, and PKA signalling pathways in trans- cinnamic acid-induced fibroblast migration}

To identify the possible molecular mechanisms of trans-cinnamic acid-induced migration, specific inhibitors of intracellular signalling were used. As shown in Figure 7, the PKA inhibitor (PKI-(6-22)-amide, $10 \mu \mathrm{M}$ ) and p38-MAPK inhibitor (SB203580, $10 \mu \mathrm{M})$ inhibited the trans-cinnamic acid-induced migration of fibroblasts by $27 \%$ and $29 \%$, respectively. Treatment with the JNK inhibitor (JNK-IN-8, $10 \mu \mathrm{M}$ ) did not cause a significant alteration in trans-cinnamic acid-induced fibroblast migration (Figure 7). These results indicate that trans-cinnamic acid exerted a positive effect on fibroblast migration via specific mechanisms.

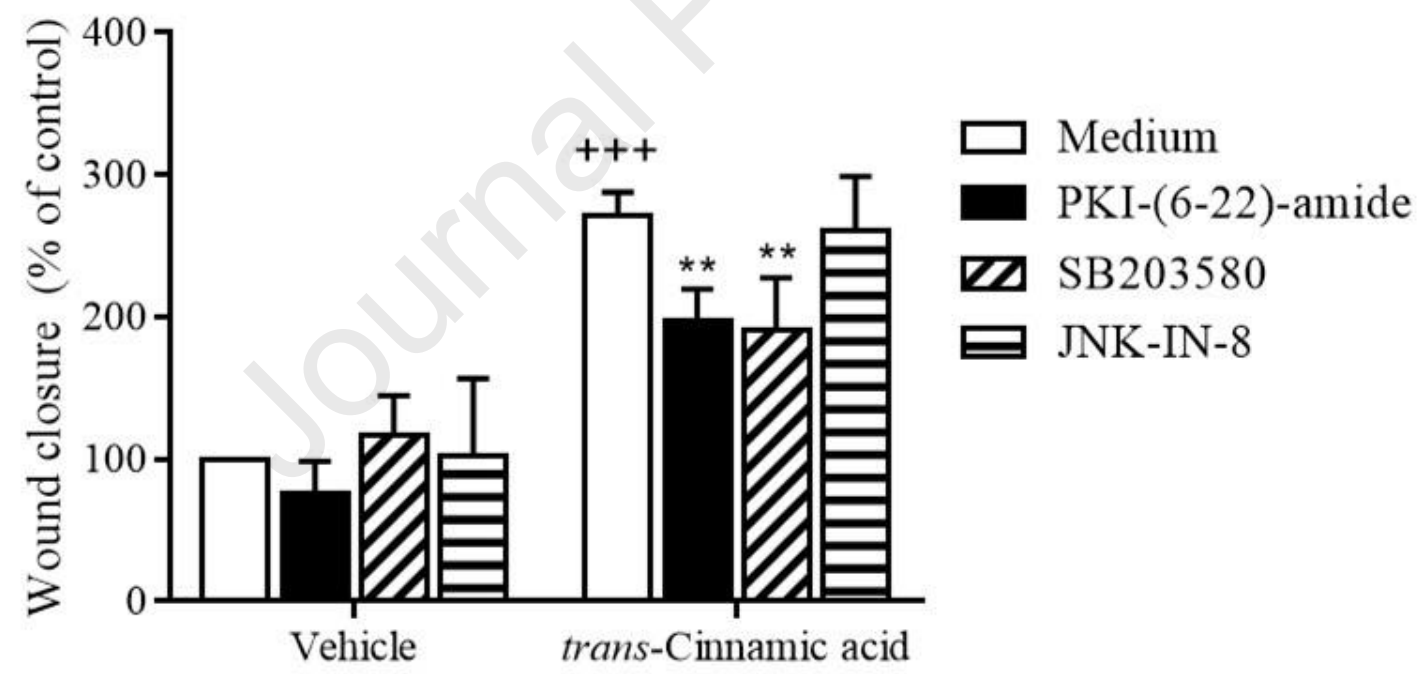

Figure 7. Inhibition of PKA and p38-MAPK but not JNK signalling pathways attenuates fibroblast migration induced by trans-cinnamic acid. Scratch wounds were created in cell monolayers of fibroblasts using a sterile pipette tip. Then, cells were cultured only with vehicle (DMSO 0.1\% in DMEM) or PKI-(6-22)-amide (a PKA inhibitor, $10 \mu \mathrm{M}$ ), SB203580 (a p38-MAPK inhibitor, $10 \mu \mathrm{M}$ ), or JNK-IN-8 (a JNK inhibitor, $10 \mu \mathrm{M})$ in the presence of trans-cinnamic acid $(30 \mu \mathrm{M})$ for $24 \mathrm{~h}$. The bars represent mean $\pm \mathrm{SD}$ of three independent experiments, each performed in triplicate. Statistical differences were detected with two-way ANOVA followed by the Bonferroni test. $(+++) \mathrm{P}<0.001$ compared to vehicle-treated cells, $(* *) \mathrm{P}<0.01$ compared to trans-cinnamic acid-treated cells. 


\subsection{Effect of trans-cinnamic acid on ECM deposition by fibroblasts}

Considering the importance of the ECM for the various functions of fibroblasts, including migration, we evaluated whether trans-cinnamic acid treatment could affect ECM protein synthesis. To this end, fibroblasts were exposed for $30 \mathrm{~h}$ to trans-cinnamic acid and the laminin, fibronectin, and collagen type I production was assessed by immunofluorescence analysis. As shown in Figure 8A, cells treated with vehicle showed a basal level of laminin protein production organized around the cell nucleus. The treatment with trans-cinnamic acid $(30 \mu \mathrm{M})$ intensified this immunofluorescence staining of cytoplasmic laminin. Image analysis showed a $30 \%$ increase in the intracytoplasmic fluorescence reflecting laminin levels after treatment (Figure 8B). The intracytoplasmic level of fibronectin in fibroblasts treated with vehicle was relatively low and appeared to be organized in small clusters around the cell nucleus (Figure 8A). The treatment with trans-cinnamic acid caused a significant reduction in the amount of fibronectin produced by fibroblasts. This reduction was confirmed after image analysis showed a $27 \%$ decrease in the cytoplasmic fluorescence for fibronectin after treatment with trans-cinnamic acid (Figure 8B). When the collagen type I expression was evaluated, fibroblasts treated with vehicle exhibited a weak immunofluorescence staining that was diffused in the cytoplasm (Figure 8A). Treatment with trans-cinnamic acid $(30 \mu \mathrm{M})$ increased the immunofluorescence staining of collagen type $I$ in cells. When the image was analysed, it showed an increase in collagen type I content by $45 \%$ in the intracytoplasmic fluorescence (Figure 8B). This immuno-labelling of collagen type $\mathrm{I}$ in the fibroblasts was increased after trans-cinnamic acid treatment $(30 \mu \mathrm{M})$. 
Analysis of this image showed an increase by $45 \%$ in the intracytoplasmic fluorescence for collagen type I content (Figure 8B).

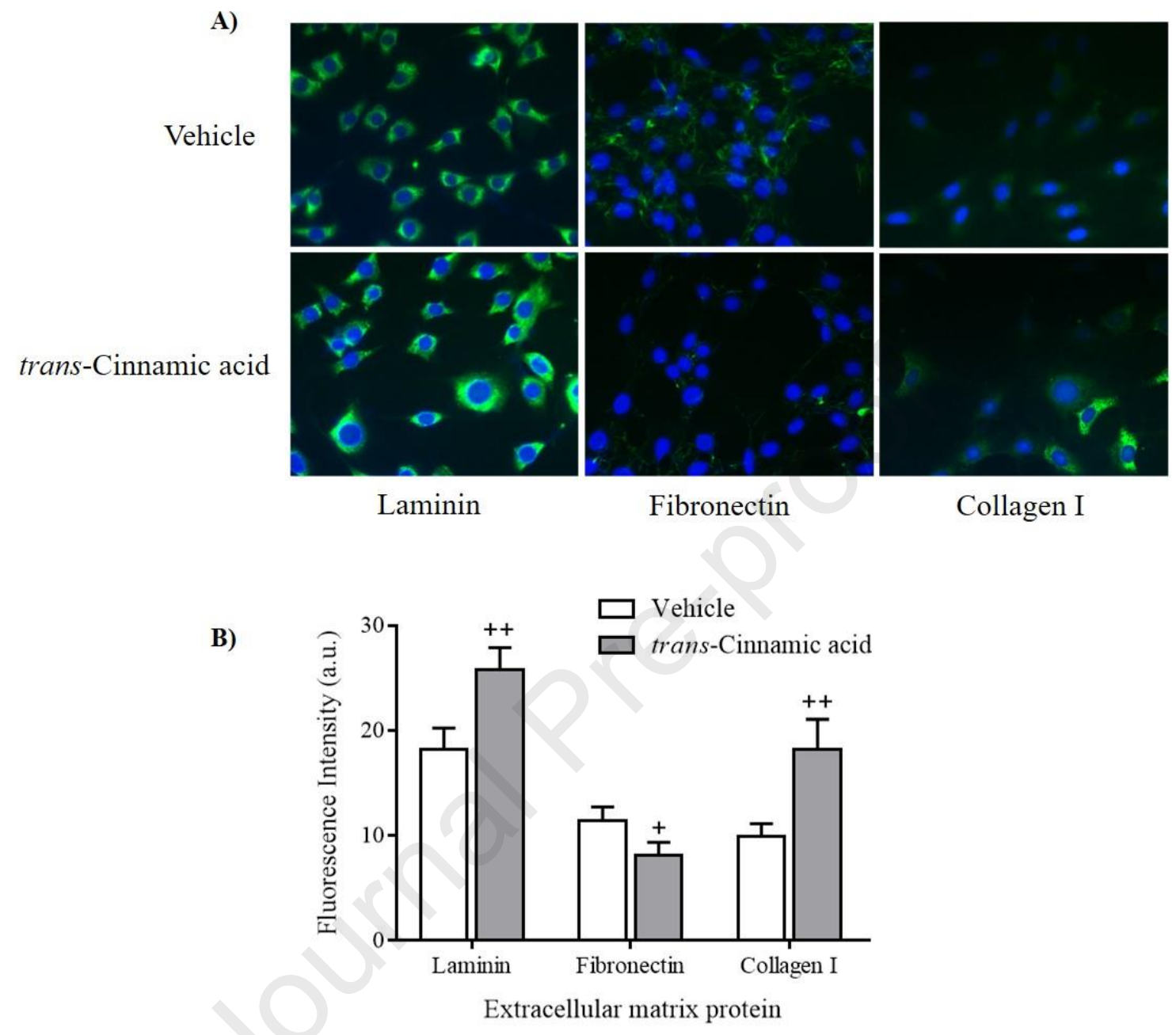

Figure 8. Effect of trans-cinnamic acid on the levels of laminin, fibronectin, and collagen type I in fibroblasts using immunofluorescence analysis. A) Fibroblasts were cultured with or without $30 \mu \mathrm{M}$ trans-cinnamic acid, and after $24 \mathrm{~h}$, the cells were fixed and extracellular matrix was immunostained using antibodies against laminin, fibronectin, and collagen type I. Nuclei were stained with DAPI. Each panel shows an image of one representative field from three independent experiments. B) Graph showing the results of the quantification of extracellular matrix synthesis of images from panel A. Bars represent mean \pm SD of three independent experiments, each performed in triplicate. Statistical significance between groups was determined by ANOVA followed by Bonferroni's test. $(+) \mathrm{P}<0.05$ and $(++) \mathrm{P}<0.01$ compared with respective vehicle-treated group. 


\section{DISCUSSION}

Hydroxycinnamic acid derivatives constitute a class of compounds originating from plants with a wide range of pharmacological effects that may be useful for treating various pathological conditions, including cutaneous wounds [26, 27]. In the healing process, the migration of fibroblast towards the injury area is a vital mechanism behind natural wound healing [28]. Thus, identification of compounds that can improve fibroblast migration can lead to the discovery of new and cost-effective drugs for treating wounds that do not heal. In the present study, we demonstrated that transcinnamic acid, but not its derivatives $p$-coumaric acid and methyl cinnamate, enhanced the migration of fibroblasts in vitro by a signalling mechanism involving PKA and p38MAPK pathways. Additionally, we also identified a modulatory effect of transcinnamic acid on the production of ECM, which resulted in an increase of synthesis of laminin and collagen type I and reduction in fibronectin synthesis by fibroblasts.

Fibroblast functions during the wound healing process are essential for restoring tissue structural integrity and maintaining tissue functionality. The initial responses of fibroblasts adjacent to the wound site include proliferation, migration, and ECM deposition [28]. It is important to mention that the lack of these functions can compromise healing, and fibroblast dysfunction is a key factor that leads to the nonhealing of chronic venous leg ulcers [29], as well as the impairment of wound healing observed in diabetic patients [30]. Thus, these observations clearly demonstrate that compounds with the ability to improve fibroblast functions can have a positive role in wound healing.

Previous studies have shown that hydroxycinnamic acids have preferential cytotoxicity for cancer cell lines $[31,32]$ and that changes in the structure of these molecules can change their biological activity or even impart new activities [26]. Here, 
we used MTT assay to estimate the cytotoxic potential of the hydroxycinnamic acid derivatives. The MTT assay has been widely used in experimental research to assess cell viability [33]. In addition, the advantages of the MTT assay include ease and rapidity of performance, reproducibility of the results, and observed clinical correlation between in vitro and in vivo testing [34]. In the present study, we evaluated the in vitro cytotoxicity of trans-cinnamic acid, p-coumaric acid, and methyl cinnamate, and we noted no toxic effects on fibroblasts at dose ranges from 3-300 $\mu \mathrm{M}$ and $24 \mathrm{~h}$ exposure. This result confirms previous reports that demonstrated the absence of cytotoxicity of these hydroxycinnamic acid derivatives in fibroblasts [14, 35, 36].

Whereas that mouse fibroblastic lines are comparable to human cell lines in responsiveness to migration pattern [37], we decided to evaluated the effect of hydroxycinnamic acid derivatives on mouse fibroblast migration via the scratch assay. This assay is a standard in vitro methodology, which enables screening of substances that are able to regulate cellular migration [38]. For this, a cell-free area is created in a confluent monolayer through mechanical damage, and the cells that remain move towards the artificial gap, which allows for measuring the rate of gap closure (wound closure) [39].

In this assay, the mouse fibroblast cell lines are commonly used in screening drugs that can improve wound healing [40]. In addition, the importance of NIH/3T3 and L929 cells as model for translational study have been recognized by many biomedical and pharmaceutical companies [7]. In our study, trans-cinnamic acid, $p$-coumaric acid, or methyl cinnamate were used as a treatment during the scratch assay, and all these compounds were found to accelerate the closure of the scratched area in a timedependent manner, suggesting that these compounds have a direct effect on fibroblasts. 
These results are consistent with a previous study in which an hydroxycinnamic acid, ferulic acid, significantly improved fibroblast motility [41].

It is well-known that during a scratch assay, cells not only migrate into the gap, but also proliferate. Thus, we decided to characterize the effect of these hydroxycinnamic acid derivatives on cell cycle phases. Our results revealed that transcinnamic acid, $p$-coumaric acid, or methyl cinnamate promoted proliferation of fibroblasts, accelerating the entry of cells into the $S$ phase of the cell cycle. It is wellestablished that serum starving is the most common non-pharmaceutical method for minimizing proliferation in wound healing assays [38]. Even so, we decided to carry out the scratch assay with hydroxycinnamic acid derivatives using mitomycin $\mathrm{C}$, a drug used to arrest mitosis at various stages. To our surprise, we found that the use of mitomycin $\mathrm{C}$ prevented the migration of fibroblasts treated with $p$-coumaric acid or methyl cinnamate, but not trans-cinnamic acid, in the scratch assay. Such an effect of trans-cinnamic acid in accelerating closure of the scratched area was also observed when L929 fibroblasts were used in the scratch assay. To further confirm this effect on fibroblast motility, trans-cinnamic acid-treated cells showed markedly increased migratory activity compared with untreated cells when evaluated using transwell migration assays. These observation supports the notion that trans-cinnamic acid directly affect fibroblast migration. This selective influence on cell migration is not unique to trans-cinnamic acid, the gallic acid, a hydroxybenzoic acid occurring mostly in red fruits, also exerts migration-stimulating effects on human dermal fibroblasts without inducing proliferation [39]. Furthermore, this finding clearly shows that the chemical modifications in the structure of these compounds have a direct impact on the profile of their biological activities, indicating the need for further studies on the structure-activity relationship of these hydroxycinnamic acid derivatives. A probable, 
albeit speculative, explanation may be that the chemical structure of $p$-coumaric acid has one $-\mathrm{OH}$ moiety in its aromatic ring, while methyl cinnamate has one - $\mathrm{CH} 3$ moiety in its carboxyl group; these modifications may affect electronic charge distribution across the whole structure, bringing changes in these molecules' polarity, and causing loss of activity. Prior chemical studies have demonstrated that simple chemical modifications may result in unexpected effects in hydroxycinnamic acids, including new modes of action $[42,43]$. Further studies are required to investigate this concept.

Fibroblast migration is an event mediated by multiple intracellular signalling pathways, including protein kinase A (PKA), CREB, and p38 and JNK MAPK pathways [44]. However, despite scientific advancements in recent years, knowledge about the fibroblast signalling pathways that are activated by trans-cinnamic acid remains scarce. Thus, to evaluate whether the pro-migratory effect of trans-cinnamic acid is exerted via any intracellular signalling pathways, we evaluated fibroblast migration using the scratch assay in the presence of inhibitors of distinct signalling pathways. Our results demonstrated that inhibitors PKI-(6-22)-amide and SB203580, but not the inhibitor of JNK-IN-8, attenuated the trans-cinnamic acid-induced fibroblast migration, indicating the involvement of both signalling pathway PKA and p38-MAPK in fibroblast migration. These data are in agreement with previous studies showing that trans-cinnamic acid induces an increase in PKA and p38-MAPK phosphorylation in other cell types, such as adipocytes [45] and epithelial cells [46]. Therefore, the involvement of these intracellular signalling pathways in the positive regulation of fibroblast migration induced by trans-cinnamic acid supports the proposition of this compound as a new tool for improving fibroblast migration. However, further studies are required to determine how trans-cinnamic acid leads to both PKA and p38-MAPK activation. 
It is also worth highlighting that previous studies demonstrated that activation of PKA and p38-MAPK intracellular signalling pathways induces the upregulation of ECM production by fibroblasts [47, 48]. Considering that the deposition of laminin, collagen type I and fibronectin plays a crucial role in fibroblast migration, adhesion, and wound healing, we evaluated whether trans-cinnamic acid also affected the production of these ECM proteins. Indeed, we verified that trans-cinnamic acid increased the synthesis of laminin and collagen type I and inhibited the synthesis of fibronectin. In line with our study, previous findings have also shown this dual effect of cinnamic acid in stimulating laminin and collagen synthesis while simultaneously inhibiting fibronectin production in epidermal cells [26, 49]. Considering that ECM can induce intracellular signals or interact with transduction pathways triggered by specific receptors, thereby promoting cell migration, we can infer that trans-cinnamic acid might represent a new chemical that can induce fibroblast migration.

\section{CONCLUSION}

In conclusion, we have presented for the first time that in addition to stimulating laminin and collagen type I synthesis, trans-cinnamic acid significantly stimulates fibroblast function to promote their migration via a mechanism that seems to involve both the PKA and p38-MAPK signalling pathways. These effects might have an important role in the wound healing process and are relevant for wound therapies. 


\section{REFERENCES}

[1] Guo S, Dipietro LA. Factors affecting wound healing. J Dent Res. 2010;89:219-29.

[2] Eming SA, Martin P, Tomic-Canic M. Wound repair and regeneration: mechanisms, signaling, and translation. Sci Transl Med. 2014;6:265sr6.

[3] Pastar I, Stojadinovic O, Yin NC, Ramirez H, Nusbaum AG, Sawaya A, et al. Epithelialization in Wound Healing: A Comprehensive Review. Adv Wound Care (New Rochelle). 2014;3:445-64.

[4] Barchitta M, Maugeri A, Favara G, Magnano San Lio R, Evola G, Agodi A, et al. Nutrition and Wound Healing: An Overview Focusing on the Beneficial Effects of Curcumin. Int J Mol Sci. 2019;20.

[5] Chen SL, Yu H, Luo HM, Wu Q, Li CF, Steinmetz A. Conservation and sustainable use of medicinal plants: problems, progress, and prospects. Chin Med. 2016;11:37.

[6] Agra, Ferro JN, Barbosa FT, Barreto E. Triterpenes with healing activity: A systematic review. J Dermatolog Treat. 2015;26:465-70.

[7] Sarandy MM, Novaes RD, Xavier AA, Vital CE, Leite JPV, Melo F, et al. Hydroethanolic Extract of Strychnos pseudoquina Accelerates Skin Wound Healing by Modulating the Oxidative Status and Microstructural Reorganization of Scar Tissue in Experimental Type I Diabetes. Biomed Res Int. 2017;2017:9538351.

[8] Harikarnpakdee S, Chowjarean V. Grammatophyllum speciosum Ethanolic Extract Promotes Wound Healing in Human Primary Fibroblast Cells. Int J Cell Biol. 2018;2018:7836869.

[9] Pereira LX, Silva HKC, Longatti TR, Silva PP, Di Lorenzo Oliveira C, de Freitas Carneiro Proietti $A B$, et al. Achyrocline alata potentiates repair of skin full thickness excision in mice. J Tissue Viability. 2017;26:289-99.

[10] Herrmann K. Occurrence and content of hydroxycinnamic and hydroxybenzoic acid compounds in foods. Crit Rev Food Sci Nutr. 1989;28:315-47.

[11] Kasprzak K, Oniszczuk T, Wojtowicz A, Waksmundzka-Hajnos M, Olech M, Nowak R, et al. Phenolic Acid Content and Antioxidant Properties of Extruded Corn Snacks Enriched with Kale. J Anal Methods Chem. 2018;2018:7830546.

[12] Nagasaka R, Chotimarkorn C, Shafiqul IM, Hori M, Ozaki H, Ushio H. Anti-inflammatory effects of hydroxycinnamic acid derivatives. Biochem Biophys Res Commun. 2007;358:615-9.

[13] El-Seedi HR, El-Said AM, Khalifa SA, Goransson U, Bohlin L, Borg-Karlson AK, et al. Biosynthesis, natural sources, dietary intake, pharmacokinetic properties, and biological activities of hydroxycinnamic acids. J Agric Food Chem. 2012;60:10877-95.

[14] Hseu YC, Korivi M, Lin FY, Li ML, Lin RW, Wu JJ, et al. Trans-cinnamic acid attenuates UVAinduced photoaging through inhibition of AP-1 activation and induction of Nrf2-mediated antioxidant genes in human skin fibroblasts. J Dermatol Sci. 2018;90:123-34.

[15] Yilmaz S, Ergun S. Trans-cinnamic acid application for rainbow trout (Oncorhynchus mykiss): I. Effects on haematological, serum biochemical, non-specific immune and head kidney gene expression responses. Fish Shellfish Immunol. 2018;78:140-57.

[16] Pragasam SJ, Venkatesan V, Rasool M. Immunomodulatory and anti-inflammatory effect of p-coumaric acid, a common dietary polyphenol on experimental inflammation in rats. Inflammation. 2013;36:169-76.

[17] Yamaguchi M, Weitzmann MN. The bone anabolic carotenoid p-hydroxycinnamic acid promotes osteoblast mineralization and suppresses osteoclast differentiation by antagonizing NF-kappaB activation. Int J Mol Med. 2012;30:708-12.

[18] Murakami Y, Kawata A, Suzuki S, Fujisawa S. Cytotoxicity and Pro-/Anti-inflammatory Properties of Cinnamates, Acrylates and Methacrylates Against RAW264.7 Cells. In Vivo. 2018;32:1309-22.

[19] Park SH, Ko JW, Shin NR, Shin DH, Cho YK, Seo CS, et al. 4-Hydroxycinnamic acid protects mice from cigarette smoke-induced pulmonary inflammation via MAPK pathways. Food Chem Toxicol. 2017;110:151-5. 
[20] Nikoloudaki G, Brooks S, Peidl AP, Tinney D, Hamilton DW. JNK Signaling as a Key Modulator of Soft Connective Tissue Physiology, Pathology, and Healing. Int J Mol Sci. 2020;21. [21] Cardoso SH, de Oliveira CR, Guimaraes AS, Nascimento J, de Oliveira Dos Santos Carmo J, de Souza Ferro JN, et al. Synthesis of newly functionalized 1,4-naphthoquinone derivatives and their effects on wound healing in alloxan-induced diabetic mice. Chem Biol Interact. 2018;291:55-64.

[22] Suvarna K, Honda K, Kondoh Y, Osada H, Watanabe N. Identification of a small-molecule ligand of beta-arrestin1 as an inhibitor of stromal fibroblast cell migration accelerated by cancer cells. Cancer Med. 2018;7:883-93.

[23] Pozarowski P, Darzynkiewicz Z. Analysis of cell cycle by flow cytometry. Methods Mol Biol. 2004;281:301-11.

[24] Smaniotto S, de Mello-Coelho V, Villa-Verde DM, Pleau JM, Postel-Vinay MC, Dardenne M, et al. Growth hormone modulates thymocyte development in vivo through a combined action of laminin and CXC chemokine ligand 12. Endocrinology. 2005;146:3005-17.

[25] Dong Z, Zhao X, Tai W, Lei W, Wang Y, Li Z, et al. IL-27 attenuates the TGF-beta1-induced proliferation, differentiation and collagen synthesis in lung fibroblasts. Life Sci. 2016;146:2433.

[26] Taofiq O, Gonzalez-Paramas AM, Barreiro MF, Ferreira IC. Hydroxycinnamic Acids and Their Derivatives: Cosmeceutical Significance, Challenges and Future Perspectives, a Review. Molecules. 2017;22.

[27] Amigo-Benavent M, Wang S, Mateos R, Sarria B, Bravo L. Antiproliferative and cytotoxic effects of green coffee and yerba mate extracts, their main hydroxycinnamic acids, methylxanthine and metabolites in different human cell lines. Food Chem Toxicol. 2017; 106:125-38.

[28] Tracy LE, Minasian RA, Caterson EJ. Extracellular Matrix and Dermal Fibroblast Function in the Healing Wound. Adv Wound Care (New Rochelle). 2016;5:119-36.

[29] Wall IB, Moseley R, Baird DM, Kipling D, Giles P, Laffafian I, et al. Fibroblast dysfunction is a key factor in the non-healing of chronic venous leg ulcers. J Invest Dermatol. 2008;128:252640.

[30] Jhamb S, Vangaveti VN, Malabu UH. Genetic and molecular basis of diabetic foot ulcers: Clinical review. J Tissue Viability. 2016;25:229-36.

[31] Matsuno T, Jung SK, Matsumoto Y, Saito M, Morikawa J. Preferential cytotoxicity to tumor cells of 3,5-diprenyl-4-hydroxycinnamic acid (artepillin C) isolated from propolis. Anticancer Res. 1997;17:3565-8.

[32] Menezes J, Edraki N, Kamat SP, Khoshneviszadeh M, Kayani Z, Mirzaei HH, et al. Long Chain Alkyl Esters of Hydroxycinnamic Acids as Promising Anticancer Agents: Selective Induction of Apoptosis in Cancer Cells. J Agric Food Chem. 2017;65:7228-39.

[33] Kumar P, Nagarajan A, Uchil PD. Analysis of Cell Viability by the MTT Assay. Cold Spring Harb Protoc. 2018;2018.

[34] Sasaki T, Tamaki J, Nishizawa K, Kojima T, Tanaka R, Moriya R, et al. Evaluation of cell viability and metabolic activity of a 3D cultured human epidermal model using a dynamic autoradiographic technique with a PET radiopharmaceutical. Sci Rep. 2019;9:10685.

[35] Seok JK, Boo YC. p-Coumaric Acid Attenuates UVB-Induced Release of Stratifin from Keratinocytes and Indirectly Regulates Matrix Metalloproteinase 1 Release from Fibroblasts. Korean J Physiol Pharmacol. 2015;19:241-7.

[36] Panel RE, Belsito D, Bickers D, Bruze M, Calow P, Greim H, et al. A toxicologic and dermatologic assessment of related esters and alcohols of cinnamic acid and cinnamyl alcohol when used as fragrance ingredients. Food Chem Toxicol. 2007;45 Suppl 1:S1-23.

[37] Lan T, Hung SH, Su X, Wong SWK, Tseng Y. Integrating transient cellular and nuclear motions to comprehensively describe cell migration patterns. Sci Rep. 2018;8:1488.

[38] Jonkman JE, Cathcart JA, Xu F, Bartolini ME, Amon JE, Stevens KM, et al. An introduction to the wound healing assay using live-cell microscopy. Cell Adh Migr. 2014;8:440-51. 
[39] Liang CC, Park AY, Guan JL. In vitro scratch assay: a convenient and inexpensive method for analysis of cell migration in vitro. Nat Protoc. 2007;2:329-33.

[40] Pusnik M, Imeri M, Deppierraz G, Bruinink A, Zinn M. The agar diffusion scratch assay--A novel method to assess the bioactive and cytotoxic potential of new materials and compounds. Sci Rep. 2016;6:20854.

[41] San Miguel SM, Opperman LA, Allen EP, Zielinski J, Svoboda KK. Antioxidants counteract nicotine and promote migration via RacGTP in oral fibroblast cells. J Periodontol. 2010;81:1675-90.

[42] Calabriso N, Scoditti E, Massaro M, Pellegrino M, Storelli C, Ingrosso I, et al. Multiple antiinflammatory and anti-atherosclerotic properties of red wine polyphenolic extracts: differential role of hydroxycinnamic acids, flavonols and stilbenes on endothelial inflammatory gene expression. Eur J Nutr. 2016;55:477-89.

[43] Razzaghi-Asl N, Garrido J, Khazraei H, Borges F, Firuzi O. Antioxidant properties of hydroxycinnamic acids: a review of structure- activity relationships. . Current Medicinal Chemistry 2013;20:15.

[44] Cargnello M, Roux PP. Activation and function of the MAPKs and their substrates, the MAPK-activated protein kinases. Microbiol Mol Biol Rev. 2011;75:50-83.

[45] Razzaghi-Asl N, Garrido J, Khazraei H, Borges F, Firuzi O. Antioxidant properties of hydroxycinnamic acids: a review of structure- activity relationships. Curr Med Chem. 2013;20:4436-50.

[46] Chen HH, Wang TC, Lee YC, Shen PT, Chang JY, Yeh TK, et al. Novel Nrf2/ARE activator, trans-Coniferylaldehyde, induces a HO-1-mediated defense mechanism through a dual p38alpha/MAPKAPK-2 and PK-N3 signaling pathway. Chem Res Toxicol. 2015;28:1681-92.

[47] Lv T, Du Y, Cao N, Zhang S, Gong Y, Bai Y, et al. Proliferation in cardiac fibroblasts induced by beta1-adrenoceptor autoantibody and the underlying mechanisms. Sci Rep. 2016;6:32430.

[48] Schiller M, Dennler S, Anderegg U, Kokot A, Simon JC, Luger TA, et al. Increased cAMP levels modulate transforming growth factor-beta/Smad-induced expression of extracellular matrix components and other key fibroblast effector functions. J Biol Chem. 2010;285:409-21.

[49] Gunia-Krzyzak A, Sloczynska K, Popiol J, Koczurkiewicz P, Marona H, Pekala E. Cinnamic acid derivatives in cosmetics: current use and future prospects. Int J Cosmet Sci. 2018;40:35666. 

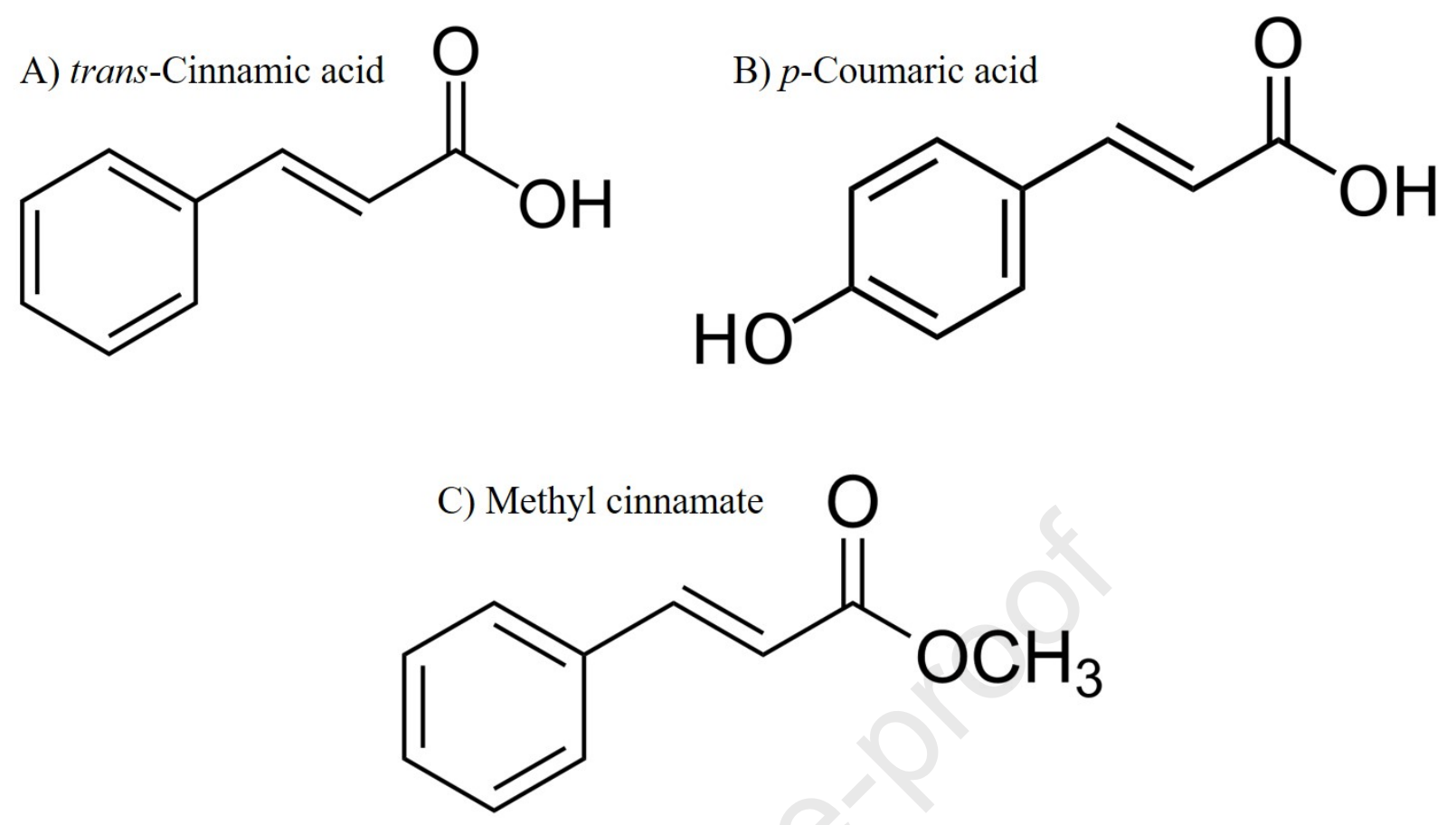


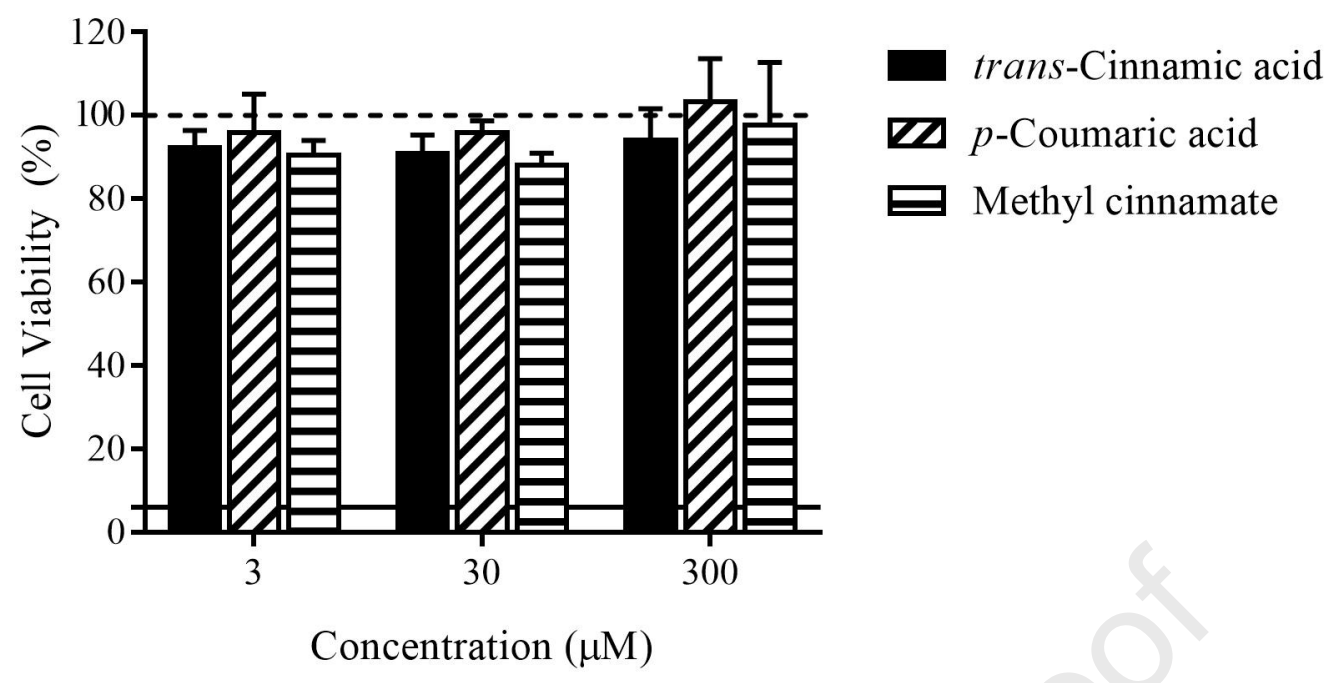




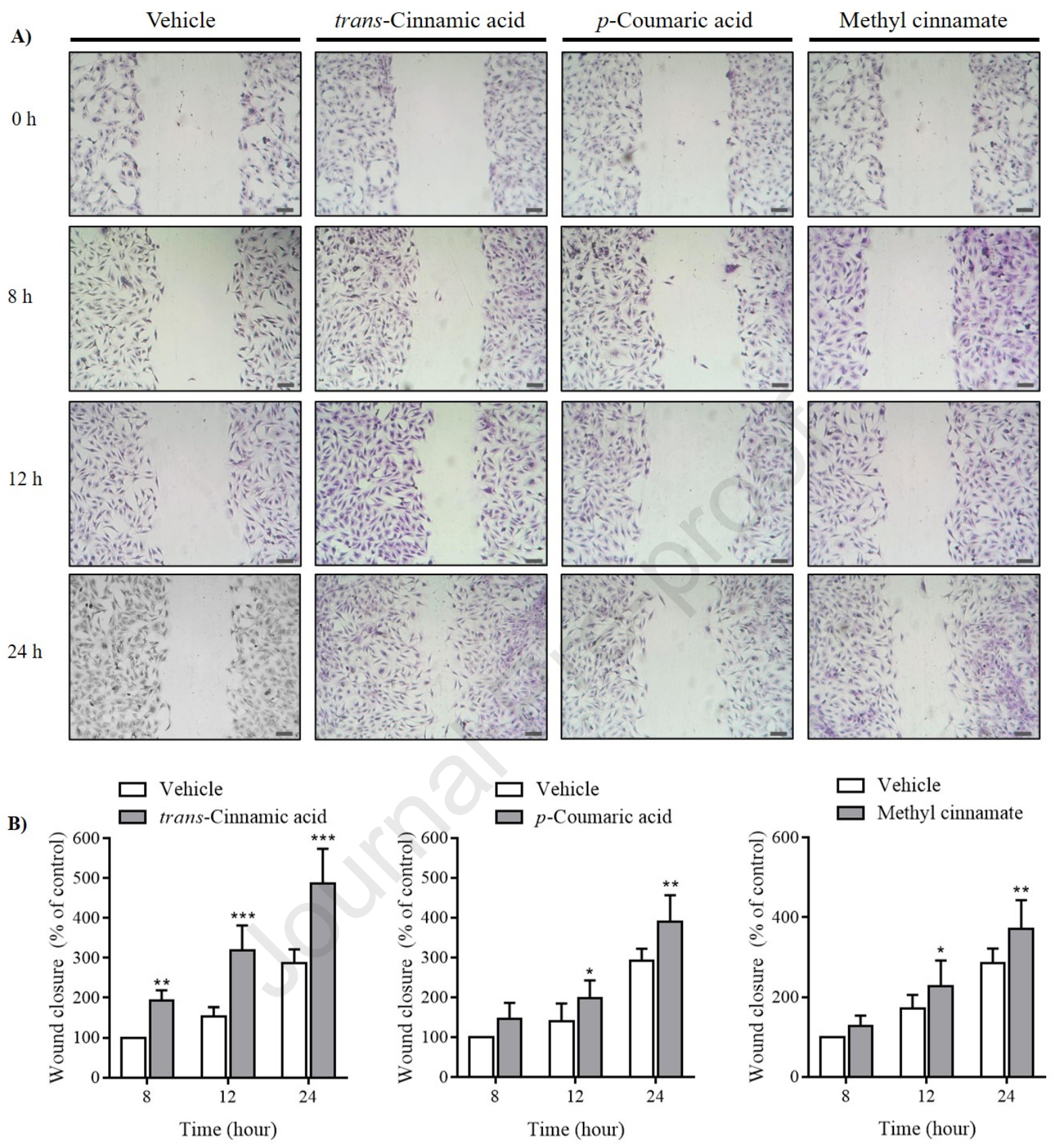



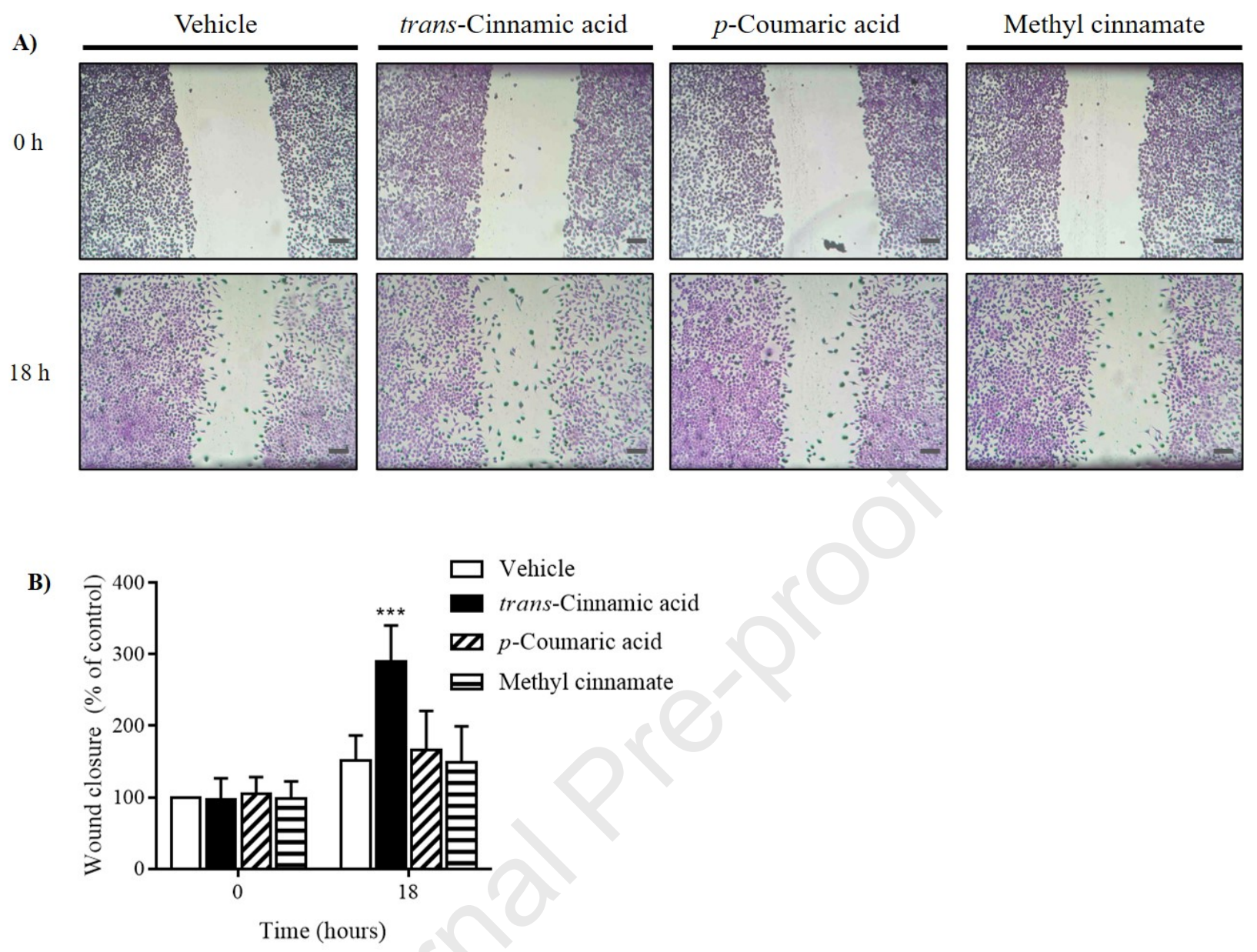

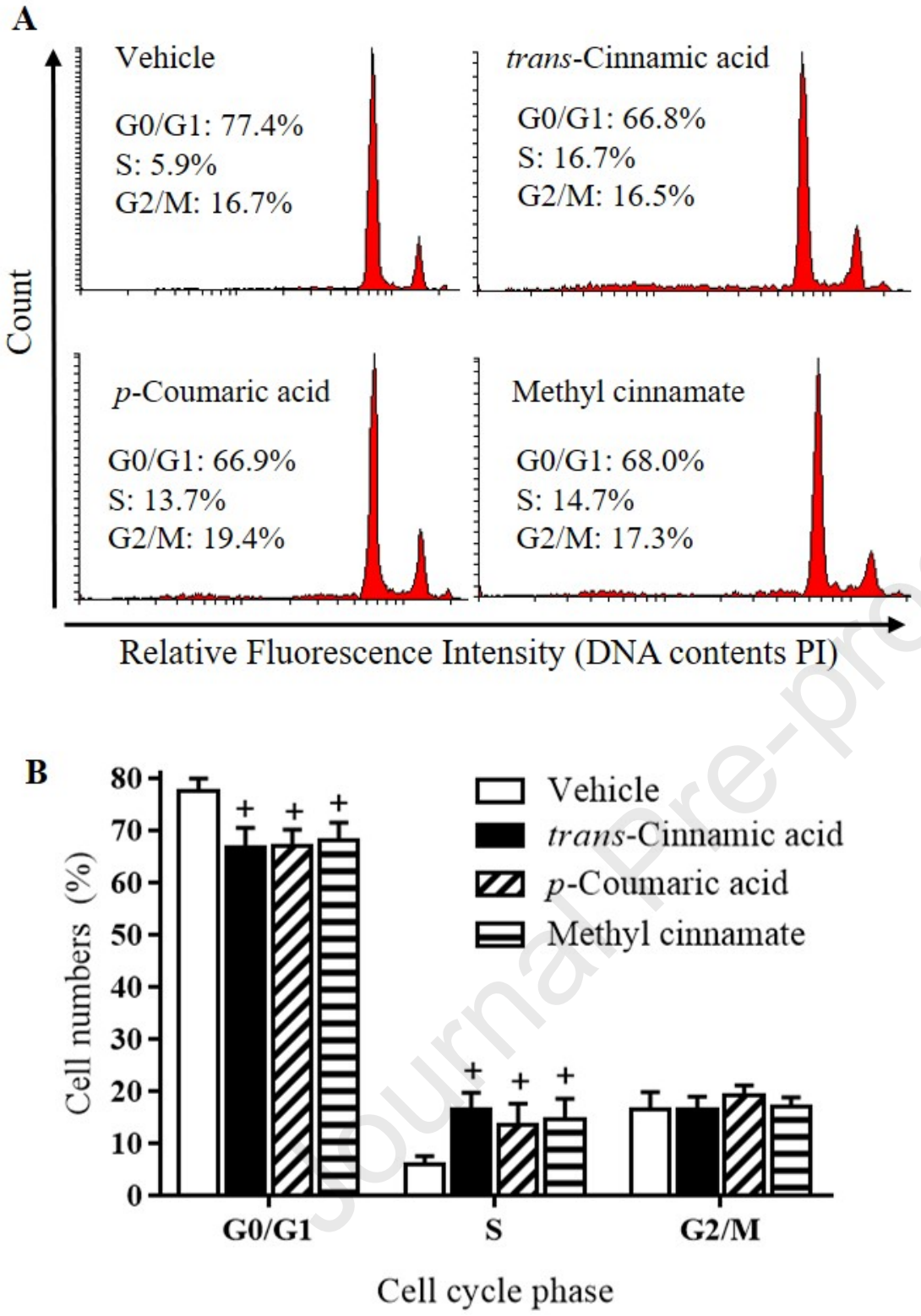


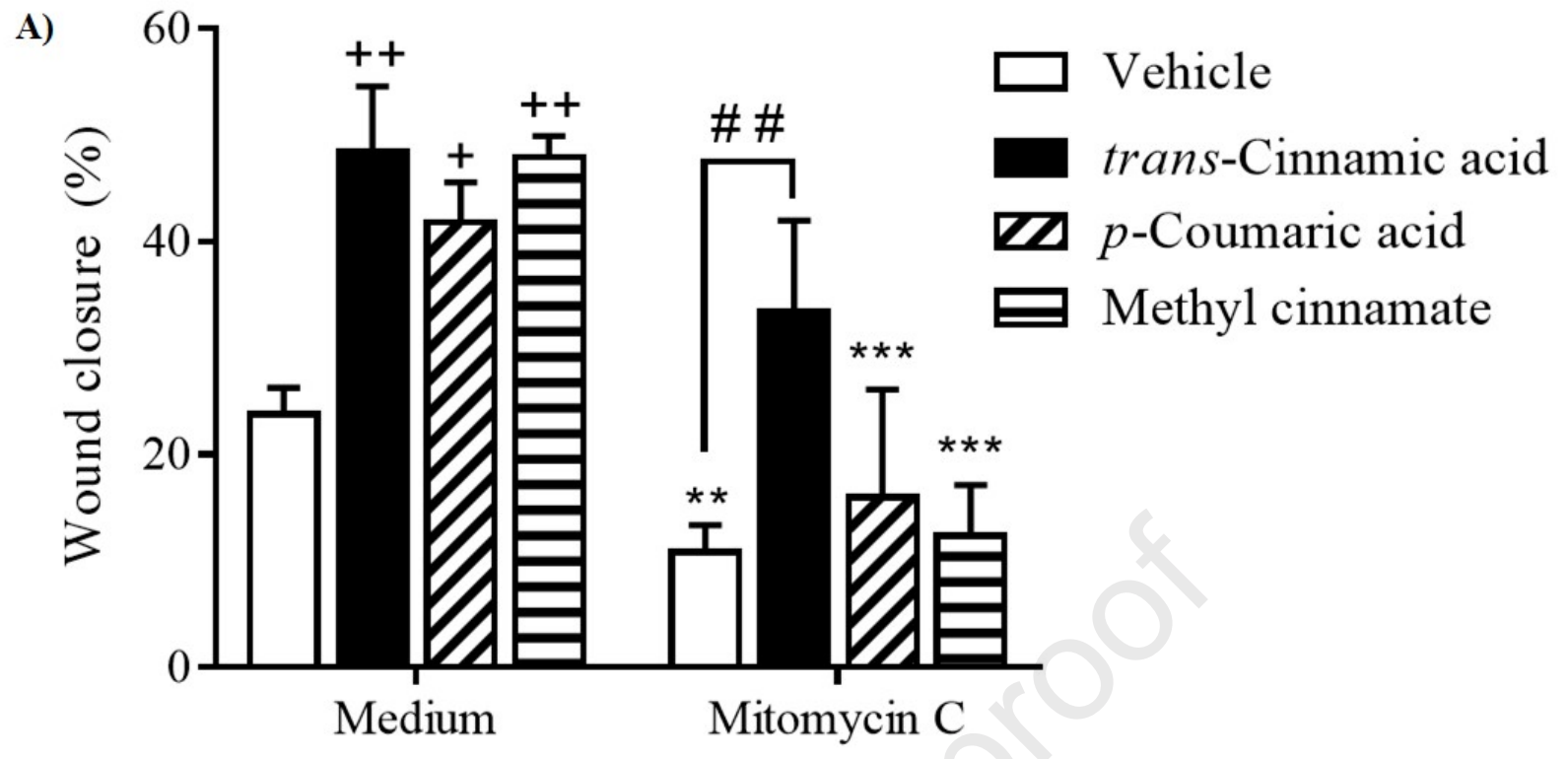

B)

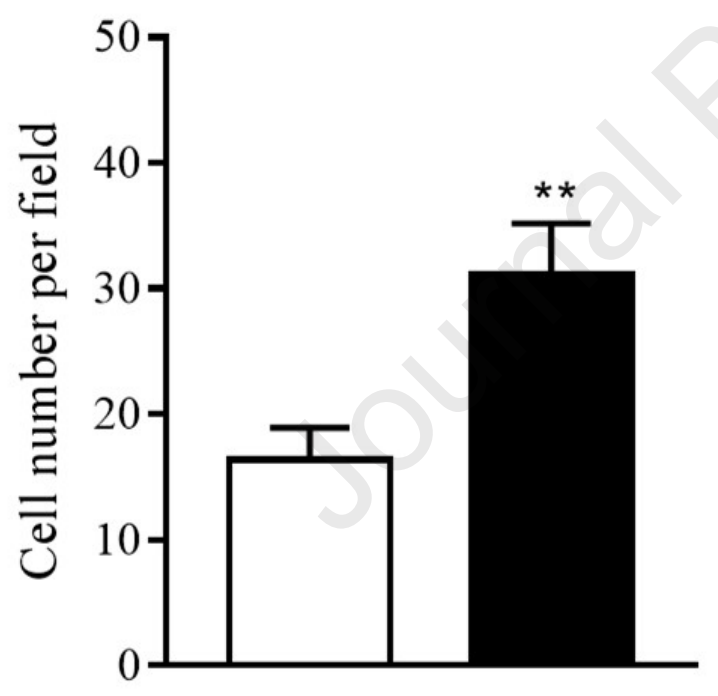

$\square$ Vehicle

trans-Cinnamic acid 


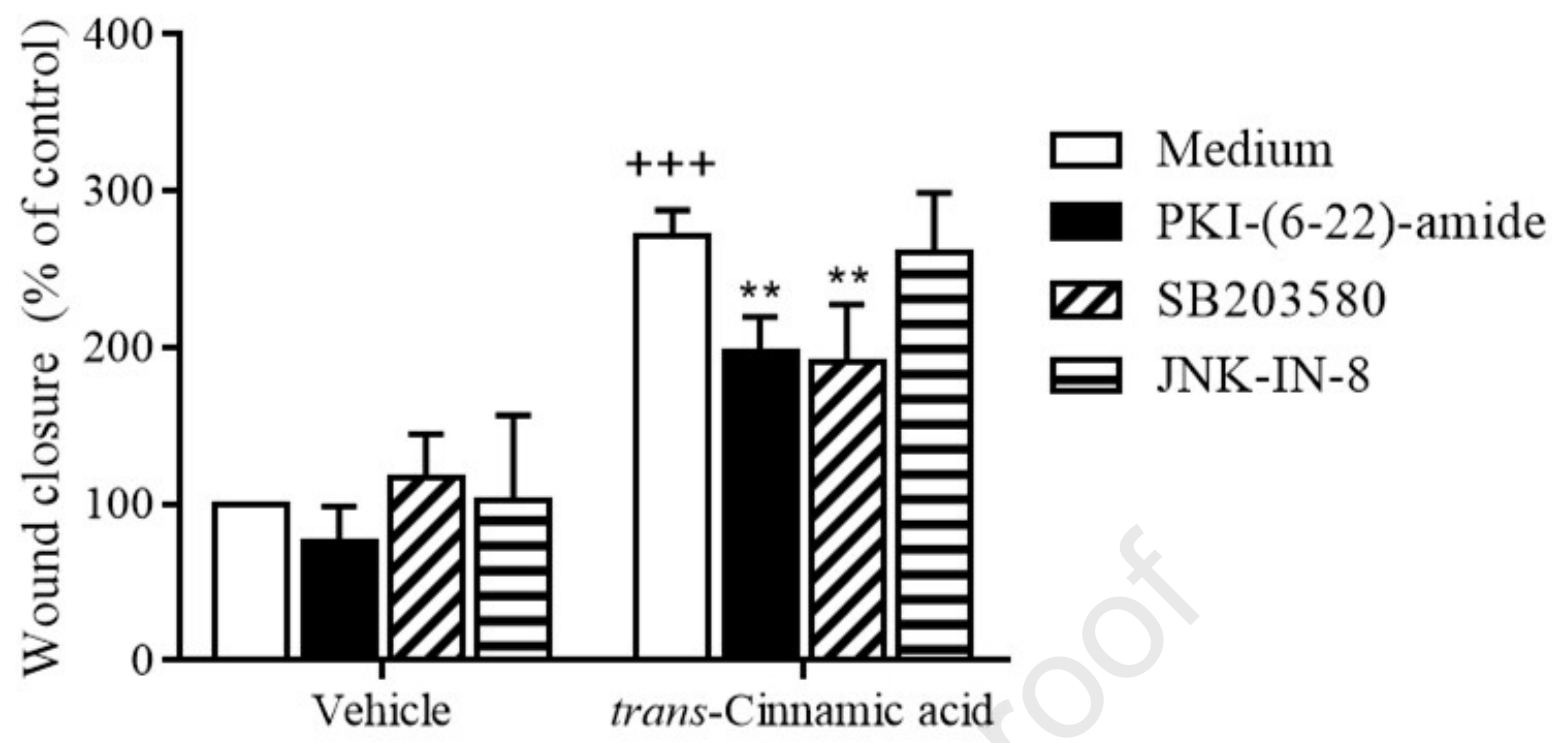




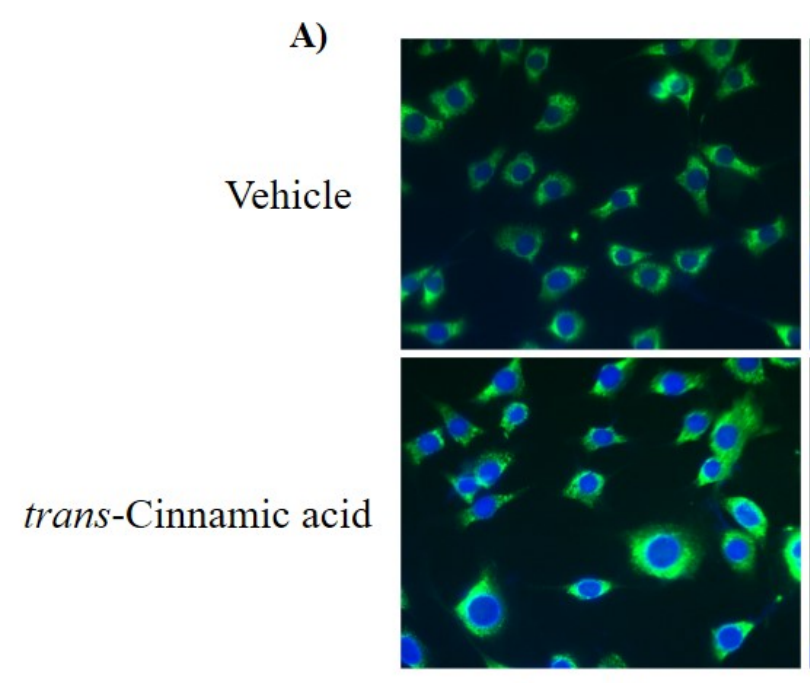

Laminin
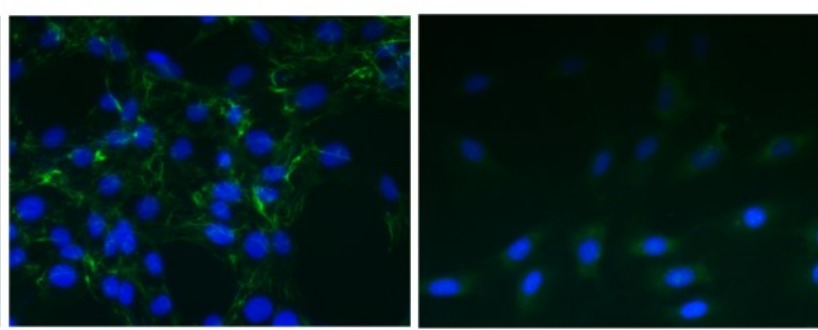

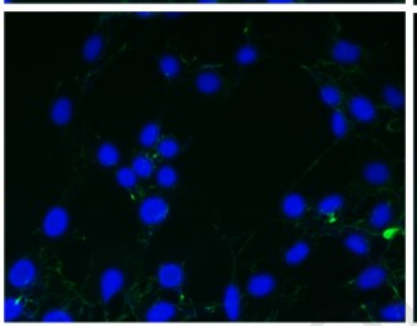

Fibronectin

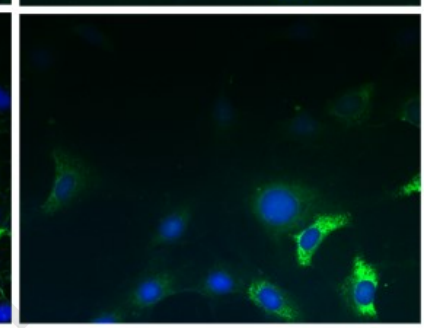

Collagen I

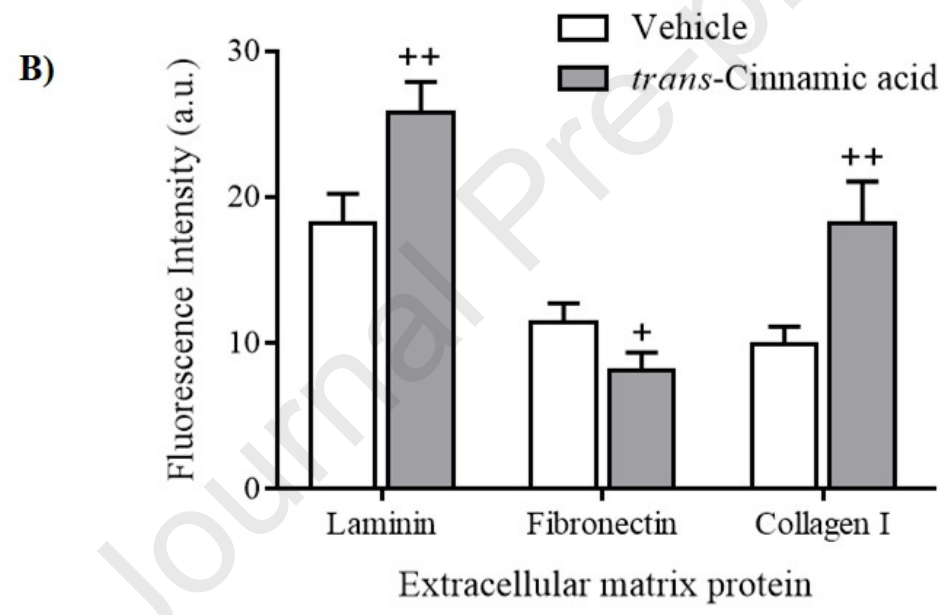




\section{Highlights}

- Treatment with trans-cinnamic acid, but not methyl cinnamate or $p$-coumaric acid, caused an increase in fibroblasts migration.

- trans-Cinnamic acid-induced fibroblast migration was dependent of PKA and p38-

MAPK signaling pathways.

- trans-Cinnamic acid provoked in fibroblasts the synthesis of laminin and collagen type 1 , but not of fibronectin. 


\section{Declaration of interests}

The authors declare that they have no known competing financial interests or personal relationships that could have appeared to influence the work reported in this paper. 